\title{
On the radiative impact of aerosols on photolysis rates: comparison of simulations and observations in the Lampedusa island during the ChArMEx/ADRIMED campaign
}

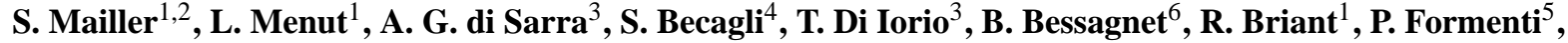 \\ J.-F. Doussin ${ }^{5}$, J. L. Gómez-Amo ${ }^{3,7}$, M. Mallet $^{8}$, G. Rea ${ }^{1}$, G. Siour ${ }^{5}$, D. M. Sferlazzo ${ }^{9}$, R. Traversi ${ }^{4}$, R. Udisti ${ }^{4}$, and \\ S. Turquety ${ }^{1}$ \\ ${ }^{1}$ Laboratoire de Météorologie Dynamique, IPSL, CNRS, École Polytechnique, École Normale Supérieure, Université Paris 6, \\ UMR8539 91128 Palaiseau CEDEX, France \\ ${ }^{2}$ École Nationale des Ponts et Chaussées - Paristech, Cité Descartes, 6-8 Avenue Blaise Pascal, \\ 77455 Champs-sur-Marne, France \\ ${ }^{3}$ ENEA, Laboratory for Earth Observations and Analyses, Via Anguillarese 301, 00123 Roma, Italy \\ ${ }^{4}$ Department of Chemistry, University of Florence, Sesto Fiorentino, Florence, 50019, Italy \\ ${ }^{5}$ LISA (Laboratoire Inter-Universitaire des Systèmes Atmosphériques), UMR CNRS 7583, Université Paris Est Créteil et \\ Université Paris Diderot, Institut Pierre Simon Laplace, Créteil, France \\ ${ }^{6}$ National Institute for Industrial Environment and Risks (INERIS), Parc Technologique ALATA, \\ 60550 Verneuil-en-Halatte, France \\ ${ }^{7}$ Dpt. Earth Physics and Thermodynamics, University of Valencia, Dr. Moliner, 50, 46100, Burjassot (Valencia), Spain \\ ${ }^{8}$ Laboratoire d'Aérologie, Observatoire Midi-Pyrénées, 14 Avenue Edouard Belin, 31400 Toulouse, France \\ ${ }^{9}$ ENEA, Laboratory for Earth Observations and Analyses, Contrada Grecale, 92010, Lampedusa, Italy
}

Correspondence to: S. Mailler (sylvain.mailler@1md.polytechnique.fr)

Received: 25 November 2014 - Published in Atmos. Chem. Phys. Discuss.: 11 March 2015

Revised: 21 December 2015 - Accepted: 3 January 2016 - Published: 3 February 2016

\begin{abstract}
The Mediterranean basin is characterized by large concentrations of aerosols from both natural and anthropogenic sources. These aerosols affect tropospheric photochemistry by modulating the photolytic rates. Three simulations of the atmospheric composition at basin scale have been performed with the CHIMERE chemistry-transport model for the period from 6 June to 15 July 2013 covered by the ADRIMED campaign, a campaign of intense measurements in the western Mediterranean basin. One simulation takes into account the radiative effect of the aerosols on photochemistry, the second one does not, and the third one is designed to quantify the model sensitivity to a bias in the ozone column.

These simulations are compared to satellite and groundbased measurements, with a particular focus on the area of Lampedusa. Values of the aerosol optical depth (AOD) are obtained from the MODIS instrument on the AQUA and
\end{abstract}

TERRA satellites as well as from stations in the AERONET network and from the MFRSR sun photometer deployed at Lampedusa. Additional measurements from instruments deployed at Lampedusa either permanently or exceptionally are used for other variables: MFRSR sun photometer for AOD, diode array spectrometer for actinic fluxes, LIDAR for the aerosol backscatter, sequential sampler for speciation of aerosol and Brewer spectrophotometer for the total ozone column. It is shown that CHIMERE has a significant ability to reproduce observed peaks in the AOD, which in Lampedusa are mainly due to dust outbreaks during the ADRIMED period, and that taking into account the radiative effect of the aerosols in CHIMERE considerably improves the ability of the model to reproduce the observed day-to-day variations of the photolysis rate of ozone to $\mathrm{O}_{2}$ and $\mathrm{O}\left({ }^{1} \mathrm{D}\right), J\left(\mathrm{O}^{1} \mathrm{D}\right)$, and that of $\mathrm{NO}_{2}$ to $\mathrm{NO}$ and $\mathrm{O}\left({ }^{3} \mathrm{P}\right), J\left(\mathrm{NO}_{2}\right)$. While in the case of $J\left(\mathrm{O}^{1} \mathrm{D}\right)$ other variation factors such as the strato- 
spheric ozone column are very important in representing correctly the day-to-day variations, the day-to-day variations of $J\left(\mathrm{NO}_{2}\right)$ are captured almost completely by the model when the optical effects of the aerosols are taken into account.

Finally, it is shown that the inclusion of the direct radiative effect of the aerosols in the CHIMERE model leads to reduced $J\left(\mathrm{O}^{1} \mathrm{D}\right)$ and $J\left(\mathrm{NO}_{2}\right)$ values over all the simulation domain, which range from a few percents over continental Europe and the north-east Atlantic Ocean to about $20 \%$ close to and downwind from Saharan dust sources. The effect on the modelled ozone concentration is 2-fold: the effect of aerosols leads to reduced ozone concentrations over the Mediterranean Sea and continental Europe, close to the sources of $\mathrm{NO}_{x}$, but it also leads to increased ozone concentrations over remote areas such as the Sahara and the tropical Atlantic Ocean.

\section{Introduction}

The Mediterranean region is subject to large aerosol concentrations due to both anthropogenic and biogenic emissions. These large aerosol concentrations affect the radiative transfers in the Mediterranean atmosphere through the direct, semi-direct and indirect effect of the aerosols. Lampedusa, a small island located off the coasts of Sicily and Tunisia, hosts a station for climate observation run by the ENEA on its north-eastern coast $\left(35.5^{\circ} \mathrm{N}, 12.6^{\circ} \mathrm{E}\right)$. At this location, the largest contributors to this effect are the desert-dust emissions from the Sahara, the polluted air masses mostly coming from continental Europe, the sea-salt particles emitted either in the Mediterranean Sea itself or advected from the Atlantic and the particles from biomass burning, when large forest fires occur in southern Europe (Pace et al., 2006). Over the sea surface and in the neighbouring coastal areas, the contribution of sea-spray aerosols is dominant within the boundary layer. These aerosols interact dynamically with meteorology and climate through microphysical and radiative effects (Levy II et al., 2013; Rosenfeld et al., 2014). Apart from these effects on the climate and meteorology, recent studies (Casasanta et al., 2011; Gerasopoulos et al., 2012) have shown that the radiative effect of the aerosols significantly modulates the photolysis rates in the Mediterranean region, focusing on the photolysis rate of ozone to $\mathrm{O}_{2}$ and $\mathrm{O}\left({ }^{1} \mathrm{D}\right)$, $J\left(\mathrm{O}^{1} \mathrm{D}\right)$, and that of $\mathrm{NO}_{2}$ to $\mathrm{NO}$ and $\mathrm{O}\left({ }^{3} \mathrm{P}\right), J\left(\mathrm{NO}_{2}\right)$. Casasanta et al. (2011) mention a reduction of $62 \%$ in $J\left(\mathrm{O}^{1} \mathrm{D}\right)$ for a unit aerosol optical depth (AOD) at $416 \mathrm{~nm}$ when the solar zenith angle (SZA) is $60^{\circ}$. The long-term study of Gerasopoulos et al. (2012) with measurements of $J\left(\mathrm{O}^{1} \mathrm{D}\right)$ and $J\left(\mathrm{NO}_{2}\right)$ for a 5 -year period above the island of Crete showed that, for a constant solar zenith angle $\left(\mathrm{SZA}=60^{\circ}\right)$, $J\left(\mathrm{NO}_{2}\right)$ has an annual cycle that reaches about $15 \%$ of its average value, and this annual cycle is essentially driven by the seasonal variations in the composition and optical depth of aerosols. At $60^{\circ}$ zenith angle, these authors show that a sta- tistically significant correlation exists between the photolytic rates and the $\mathrm{AOD}$, with a reduction of about $10 \%$ in both $J\left(\mathrm{NO}_{2}\right)$ and $J\left(\mathrm{O}^{1} \mathrm{D}\right)$ for an AOD of 0.3 at a zenith angle of $60^{\circ}$ and about $25 \%$ for an AOD of 0.7. In particular, mineral dust causes significant absorption in the wavelengths between 300 and $400 \mathrm{~nm}$ which are determinant in tropospheric photochemistry (Savoie et al., 2000; Diaz et al., 2001; Kaufman et al., 2001). Even though the aerosols impact the tropospheric photochemistry in several ways, including radiative effects as well as heterogeneous chemistry (Bian and Zender, 2003), we will focus in this study on the direct radiative impact of aerosols on photolysis rates. It has been shown in the past (Bian et al., 2003) that this effect modifies the global budgets of $\mathrm{O}_{3}$ and other gases and that this effect is 2-fold: it leads to reduction of the ozone concentrations in the troposphere in the high- $\mathrm{NO}_{x}$ ozone-producing regions and to increases of ozone concentrations over the low- $\mathrm{NO}_{x}$ regions, particularly over the oceans.

In order to be able to evaluate and take into account the effect of aerosols on photochemistry over the Mediterranean area, a model for radiative transfer and online calculation of photochemical rates, Fast-JX (Wild et al., 2000; Bian and Prather, 2002), which is already used in various chemistry-transport models (CTMs) (Telford et al., 2013; Real and Sartelet, 2011), has been included into the CHIMERE chemistry-transport model (Menut et al., 2013). With this new development, the CHIMERE model is able to simulate the radiative impact of aerosols on photochemistry. The Fast-JX module takes into account the values provided in real time by the CTM for all aerosol species as well as for tropospheric ozone up to the top of the CHIMERE domain. The real-time model values of the meteorological variables (temperature, pressure and cloud cover) are also used by the FastJX module. Monthly climatological distributions for stratospheric ozone are taken from the McPeters et al. (1997) climatology. As the CHIMERE model takes into account all the major anthropogenic and natural sources of aerosols and trace gases in a realistic way for the Mediterranean basin (Menut et al., 2015a), the CHIMERE model including the Fast-JX module, as used in the present study, is an adequate tool to investigate the impact of the aerosols on photochemistry at least for the Mediterranean basin.

In the framework of the ChArMEx (Chemistry-Aerosol Mediterranean Experiment, http://charmex.lsce.ipsl.fr) campaign, a special operation period, ADRIMED (Aerosol Direct Radiative Impact in the Mediterranean), has been conducted during the summer of 2013 (Mallet et al., 2015). Special Operation Period 1a (SOP1a) lasts from 12 June to 5 July, covering the central part of the simulated period. Various observational data, including photolysis rates $J\left(\mathrm{O}^{1} \mathrm{D}\right)$ and $J\left(\mathrm{NO}_{2}\right)$ at the Lampedusa supersite, are available for this period, during which various episodes of desert-dust intrusions in the free troposphere above Lampedusa have occurred. For the 40 days from 6 June to 15 July 2013, two simulations were performed for an area covering the Mediter- 
ranean basin, continental Europe and the northern part of Africa. The first simulation (REF) is described and validated in Menut et al. (2015a). It includes emissions from mineral dust, biomass burning, anthropogenic and biogenic sources, as well as the radiative effect of aerosols on photochemistry. A second simulation, which we will refer to as NA (no aerosol radiative effect), is performed with exactly the same meteorology, the same emission for aerosols and trace gases, but artificially cancelling the radiative effect of aerosols by setting the real part of their refractive index to 1 and the imaginary part to 0 in the radiative transfer model, making them perfectly transparent at all wavelengths. Therefore, the differences between these two simulations reflect the direct radiative effect of aerosols on photochemistry in the CHIMERE model.

Section 2 exposes the modelling strategy used in both simulations for meteorology, atmospheric chemistry and the radiative transfers, as well as the observational data and techniques. Section 3 presents the validation of the REF simulation by comparison to AOD observations from satellite as well as from ground stations. Descriptions of the vertical structure and speciation of aerosols above Lampedusa as simulated and as observed by the measurement facilities at Lampedusa are also presented. The simulated photolytic rates $J\left(\mathrm{O}^{1} \mathrm{D}\right)$ and $J\left(\mathrm{NO}_{2}\right)$ from both simulations are also compared to the values observed at Lampedusa in order to find whether taking into account the optical effects of aerosols improve the representation of $J\left(\mathrm{O}^{1} \mathrm{D}\right)$ and $J\left(\mathrm{NO}_{2}\right)$ in the CHIMERE model. That section also contains an evaluation of model sensitivity to the optical depth of aerosols regarding the concentration of ozone over the whole simulation domain. Finally, Sect. 4 sums up and discusses the results obtained in Sect. 3.

\section{Data and methods}

\subsection{Models}

\subsubsection{Meteorology and atmospheric chemistry}

Meteorology has been modelled using the WRF (Weather Research and Forecasting) model (Michalakes et al., 2004), version 3.5.1, as described in Menut et al. (2015a), with a horizontal resolution of $60 \times 60 \mathrm{~km}^{2}$ and 28 vertical levels from the surface up to $50 \mathrm{hPa}$. This relatively coarse resolution has been chosen because many companion simulations of the reference (REF) simulation had to be performed for this and other studies in the years 2012 and 2013: three simulations for the present study as well as four other simulations in order to test the forecast skills of the model in Menut et al. (2015b) and other simulations for quantifying the importance of the various aerosol sources in Rea et al. (2015). Additionally, due to the need for simulating a huge domain in order to include the dust sources in Africa, the Arabian
Peninsula and a substantial portion of the Atlantic Ocean for dust advection, as well as northern Europe for anthropogenic sources, it was difficult to perform simulations with a finer resolution.

The surface layer scheme is based on Monin-Obukhov with Carlson-band viscous sublayer, and the planetary boundary layer physics are processed using the Yonsei University Scheme (Hong et al., 2006). The continental surfaces are treated using the Noah Land Surface Model scheme with four soil temperature and moisture layers (Chen and Dudhia, 2001), and the model uses the cumulus parameterization of Grell and Devenyi (2002).

The meteorological model is forced at its boundaries by the global hourly fields of NCEP/GFS (National Center for Environmental Forecasting/Global Forecast System), and inside the domain the main atmospheric variables (pressure, temperature, humidity and wind) are nudged towards the NCEP/GFS hourly fields using spectral nudging (von Storch et al., 2000) for wave numbers up to 3 in latitude and longitude, corresponding to wavelengths of about $2000 \mathrm{~km}$. Nudging is not performed below $850 \mathrm{hPa}$ in order to allow the regional model to create its own structures within the boundary layer. Meteorological input fields have been produced for the same domain as the CHIMERE simulation domain.

The reader is referred to Menut et al. (2015a) for the further description and validation of this meteorological simulation. These authors indicate a persistent negative bias in temperature over all but one location over 13 stations in southern Europe: the temperature bias ranges between $-4.10 \mathrm{~K}$ and $+0.87 \mathrm{~K}$ (see their Table 4). Possible causes of this bias include problems in the boundary-layer and microphysics parameterisations. In spite of this large bias and difficulties of the model to catch the diurnal cycle of the observations, they show that the correlation coefficients of the simulated vs. observed $2 \mathrm{~m}$ temperature for this simulations range between 0.87 to 0.99 for the same subset of stations, showing that the temporal evolutions of the temperature are reproduced quite correctly by this meteorological simulation.

For the island of Lampedusa, the WRF fields for temperature and wind module are shown and compared with the field data from the Lampedusa supersite (Fig. 1). As for most other locations (Menut et al., 2015a), the modelled temperature has a significant low bias. It also lacks a daily cycle compared to the in situ data, which have pronounced daytime maxima of the temperature. The lack of a daily cycle is consistent with the fact that, at the model resolution $\left(60 \times 60 \mathrm{~km}^{2}\right)$, the island of Lampedusa is not resolved, so that the modelled values reflect open-sea temperature, which is expected to be weaker than temperature over land in summer time and to have a much weaker diurnal cycle. The temperature bias is on average of about $5 \mathrm{~K}$ for daily temperature maxima and $3 \mathrm{~K}$ for daily temperature minima. As we checked that this strong temperature bias is not present in the GFS data used to nudge the WRF model, it is possible that a misconfiguration of the WRF model is the cause of this error. The impact 


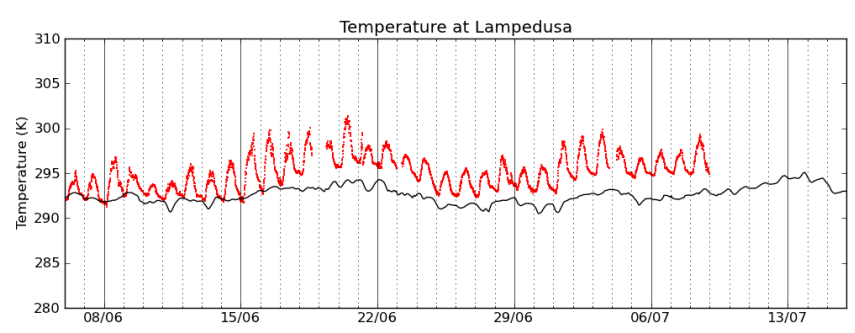

(a)

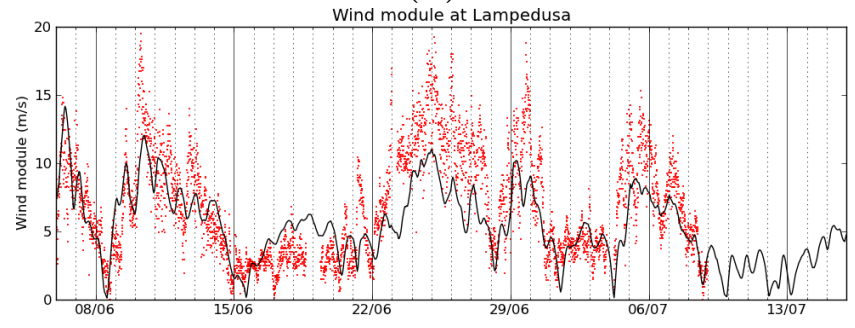

(b)

Figure 1. (a) Modelled temperature at Lampedusa (K, black line) and measured temperature (red points); (b) same as (a) but for the module of the wind at Lampedusa $\left(\mathrm{m} \mathrm{s}^{-1}\right)$.

of a $5 \mathrm{~K}$ underestimation of daytime temperature on $J\left(\mathrm{NO}_{2}\right)$ and $J\left(\mathrm{O}^{1} \mathrm{D}\right)$ photolysis rates can be estimated according to Dickerson et al. (1982). Both $J\left(\mathrm{NO}_{2}\right)$ and $J\left(\mathrm{O}^{1} \mathrm{D}\right)$ values increase with temperature, but the dependency of $J\left(\mathrm{NO}_{2}\right)$ on temperature is much weaker than that of $J\left(\mathrm{O}^{1} \mathrm{D}\right)$. While $J\left(\mathrm{O}^{1} \mathrm{D}\right)$ increases by more than $50 \%$ when temperature increases from 273 to $307 \mathrm{~K}, J\left(\mathrm{NO}_{2}\right)$ does so by less than $5 \%$. Based on the results of Dickerson et al. (1982), the impact of a cold bias of $5 \mathrm{~K}$ on $J\left(\mathrm{O}^{1} \mathrm{D}\right)$ can generate an underestimation of 5 to $10 \%$ on $J\left(\mathrm{O}^{1} \mathrm{D}\right)$ in the temperature range for daytime temperatures during the simulation period (around $295 \mathrm{~K})$ and only about $1 \%$ on $J\left(\mathrm{NO}_{2}\right)$.

Regarding the wind module, which is a key parameter in modelling sea-salt emissions, Fig. $1 \mathrm{~b}$ shows that the agreement between model and data for this parameter is quite good, even though for some periods of strong wind, for example from 23 June to 27 June, the model tends to underestimate the wind module. The error on wind direction has also been evaluated by comparison to local hourly measurements at Lampedusa. It is found that, when the wind velocity was below the median value of $5.3 \mathrm{~ms}^{-1}$, the error on wind direction is very strong, suggesting that when the synoptic wind velocity is weak, the local wind is dominated by effects such as the land breeze and sea breeze, which cannot be represented adequately at the model resolution. On the contrary, when the wind velocity is above $5.3 \mathrm{~ms}^{-1}$, the median of the absolute error on wind velocity is $35.5^{\circ}$, and the error distribution peaks in the vicinity of 0 , showing that the synoptic wind patterns are reproduced rather well by the model.

Atmospheric chemistry has been modelled with the CHIMERE chemistry transport model (Menut et al., 2013).
We used the MELCHIOR-2 (Modèle de la chimie de l'ozone à l'échelle régionale 2) chemical mechanism along with the aerosol scheme by Bessagnet et al. (2004). For this study, the emissions are taken from the HTAP (Hemispheric Transport of Air Pollution) inventory provided by the EDGAR (Emissions Database for Global Atmospheric Research) team ${ }^{1}$ and adapted to the model grid as described in Menut et al. (2013). The resulting mean $\mathrm{NO}_{x}$ emissions over the simulation domain are shown in Fig. 2. The boundary conditions for all gaseous and particulate species are taken from LMDz-INCA (Laboratoire de Météorologie Dynamique Zoomé - INteraction avec la Chimie et les Aérosols) climatology (Hauglustaine et al., 2004) except mineral dust, which is taken from the GOCART2 (Goddard Chemistry Aerosol Radiation and Transport 2) climatology (Ginoux et al., 2001) that gives the dust climatology with seven size bins instead of three for LMDZ-INCA. Since the Lampedusa island is located very far away from the domain boundaries and the domain has been designed to include all the relevant aerosol sources (mineral dust from arid areas, anthropogenic aerosols from shipping, urban and industrial emissions, etc.), the influence of the boundary conditions on aerosol content above Lampedusa is expected to be very reduced, particularly in comparison to the substantial dust plumes that have been simulated and observed at Lampedusa and other locations, as described below.

This simulation includes the representation of forest fire emissions, as described in Turquety et al. (2014). Dust emissions have been simulated as explained in Menut et al. (2015a), following the Marticorena and Bergametti (1995) scheme for saltation and Alfaro and Gomes (2001) for sandblasting. All the simulations presented were started from 1 June 2013 and lasted until 15 July 2013. The initialisation was done from the global LMDZ-INCA and GOCART2 climatologies, and the 5-day spinup period has been discarded before analysing the simulation outputs; only the 40 days from 6 June to 15 July will be analysed in the following.

Vertical discretization is on 20 levels, with 10 layers below $800 \mathrm{hPa}$ and 10 layers between $800 \mathrm{hPa}$ and the model top, which is placed at $300 \mathrm{hPa}$. The lowest model layer has $3 \mathrm{hPa}$ thickness, and all the levels between 800 and $300 \mathrm{hPa}$ have equal thickness ( $60 \mathrm{hPa}$ per layer). This vertical discretization has been chosen to permit a fine representation of both the boundary layer and the free troposphere. The radiative transfers from $300 \mathrm{hPa}$ upward are modelled using climatological ozone concentrations.

The discretization of the particle size distribution of the aerosols is performed over 10 size bins, from $39 \mathrm{~nm}$ to $40 \mu \mathrm{m}$ following a geometric progression with ratio 2 , as shown in Table 1.

\footnotetext{
${ }^{1}$ http://edgar.jrc.ec.europa.eu/htap_v2
} 


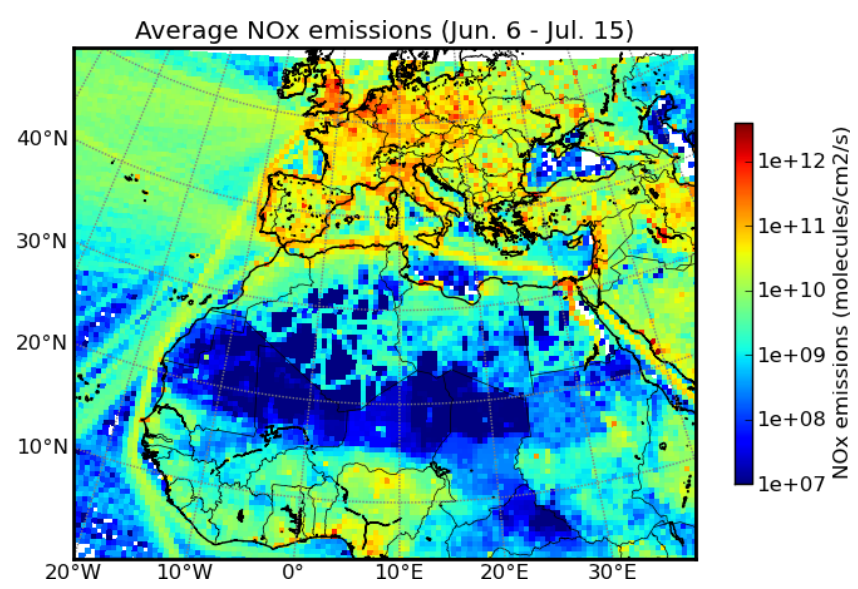

Figure 2. Mean $\mathrm{NO}_{x}$ emissions from 6 June to 15 July, in molecules $\mathrm{cm}^{-2} \mathrm{~s}^{-1}$ as used for all three simulations.

\subsubsection{Actinic fluxes and photolysis rates}

The photolysis rates have been calculated using the Fast-JX model, version 7.0b (Wild et al., 2000; Bian and Prather, 2002). At each time step and in each grid cell, this model resolves the radiative transfers in the model atmospheric column, computing the actinic fluxes at each model level and integrating them over $N$ wavelength bins in order to produce accurate photolysis rates. For our study, $N$ is set to 12, which is the value recommended by Fast-JX developers for tropospheric studies. These 12 wavelength bins include the seven standard Fast-J wavelength bins from 291 to $850 \mathrm{~nm}$, as described in Wild et al. (2000). The seven standard Fast-J wavelength bins are essentially concentrated from 291 to $412.5 \mathrm{~nm}$, which is the spectral band relevant for tropospheric photochemistry. Following the recommendations of Fast-JX model developers, five additional wavelengths bands have been used as well, from 202.5 to $291 \mathrm{~nm}$, but they are only relevant in the upper tropical troposphere, which is not included in the present study since the model top is at $300 \mathrm{hPa}$. The optical properties of the aerosols are treated at five wavelengths: 200, 300, 400, 600 and $1000 \mathrm{~nm}$. The optical treatment performed includes absorption by tropospheric and stratospheric ozone, Rayleigh scattering, Mie diffusion by liquid- and ice-water clouds, and absorption and Mie diffusion by aerosols.

The radiative indices for the main aerosol species have been taken from the ADIENT project website ${ }^{2}$. The technical and scientific choices are given in the corresponding technical report by E. J. Highwood ${ }^{3}$. For mineral dust, they are given in Table 2 and taken from the AERONET (AErosol RObotic NETwork) values of Kinne et al. (2003). Variability in the radiative indices of dust exist due to the different

\footnotetext{
${ }^{2} \mathrm{http} / / /$ www.reading.ac.uk/adient/refractiveindices.html

${ }^{3}$ http://www.reading.ac.uk/adient/REFINDS/Techreportjul09. doc
}

Table 1. Sectional bins for aerosols.

\begin{tabular}{rr}
\hline Bin number & Diameter range $(\mu \mathrm{m})$ \\
\hline 1 & $0.039-0.078$ \\
2 & $0.078-0.15$ \\
3 & $0.15-0.31$ \\
4 & $0.31-0.625$ \\
5 & $0.62-1.25$ \\
6 & $1.25-2.50$ \\
7 & $2.50-5.00$ \\
8 & $5.00-10.00$ \\
9 & $10.00-20.00$ \\
10 & $20.00-40.00$ \\
\hline
\end{tabular}

mineralogies of the source areas: clay, quartz, etc., as well as the content of iron and other minerals. The values used here are taken from a large global sampling based on AERONET measurements as described in Kinne et al. (2003) and are therefore not necessarily representative of the specific optical properties of Saharan dust.

Petzold et al. (2009) measured values of the refractive indices of Saharan dust in Morocco for three episodes. At $450 \mathrm{~nm}$, the given values are between 1.549 and 1.559 for the real part and between $2.7 \times 10^{-3}$ and $6.1 \times 10^{-3}$ for the imaginary part. These values are slightly higher than the value we used here for the real part (1.53), but the difference is very small. Regarding the imaginary part, the values given by Petzold et al. (2009) are of $2.7 \times 10^{-3}$ and $6.1 \times 10^{-3}\left(2.7 \times 10^{-3}\right.$ at $400 \mathrm{~nm}$ and $8.9 \times 10^{-3}$ at $600 \mathrm{~nm}$ in our study). They also show that the variations of the imaginary part are very strong depending on the mineralogy and source area of the dust (their Fig. 8) so that the values used here, even though they are global averages, are within the uncertainty on the refractive indices for Saharan dust in the most current research.

From these values, the extinction cross section per particle, single-scattering albedo and first seven terms of the Legendre expansion of the scattering phase function are calculated using Michael Mischenko's code (Mischenko et al., 2002), assuming log-uniform distribution within each diameter bin, and used as input of the Fast-JX radiative code. As in Bian and Zender (2003), we chose to neglect the influence of relative humidity on the optical properties of mineral dust, which has been shown to have a very small effect on the volume of dust particles (Herich et al., 2009). However, water uptake by hygroscopic species such as nitrates, sulfates and ammonium in subsaturated conditions is represented using the ISORROPIA module (Nenes et al., 1998), as described in Bessagnet et al. (2004). The optical effect of the liquidphase water generated by the hygroscopic growth of these aerosols is taken into account by the Fast-JX module as a separate aerosol species with the optical characteristics of water. Non-sphericity has not been taken into account in this study because, in our model as in most models, uncertainties related to the size distribution of dust and other aerosols are 
still large and need to be fixed before one can examine in such models the possible effect of non-sphericity.

Treatment of clouds by Fast-JX is described in, e.g. Wild et al. (2000) and Bian and Prather (2002). It is worth noting that the simulation period has been largely dominated by conditions with no cloud cover over Lampedusa. However, the spectrometer measurements show that thin clouds occurred on $6,7,10,11,13,14,24$ June and on 4 and 5 July during daytime above Lampedusa.

The photolysis rates in CHIMERE are updated every $5 \mathrm{~min}$ by calling the Fast-JX model. The AOD for each model layer is an intermediate result of the Fast-JX model, which we sum over the model layers and export for the five wavelengths used by Fast-JX in order to compare it to available observations.

One key parameter in simulating $J\left(\mathrm{O}^{1} \mathrm{D}\right)$ is the total atmospheric ozone column. Within the simulation domain (from the surface to $300 \mathrm{hPa}$, Fast-JX uses the ozone concentrations calculated within CHIMERE. Above this level, that is, for upper tropospheric and stratospheric ozone, Fast-JX uses tabulated climatological ozone concentrations. These climatological concentrations from McPeters et al. (1997), included within the Fast-JX module in its standard configuration, are given with a vertical resolution of about $2 \mathrm{~km}$ up to an altitude of about $60 \mathrm{~km}$, with monthly values for every $10^{\circ}$ latitude band. For the latitude band corresponding to Lampedusa $\left(30-40^{\circ} \mathrm{N}\right)$, the stratospheric ozone column obtained by vertically summing these climatological concentrations amounts to 248.6 DU for the month of June and 236.4 DU for the month of July. The contribution of tropospheric ozone from the CHIMERE model is about $30 \mathrm{DU}$ for all the simulation periods. Therefore, the total ozone column taken into account by the radiative transfer model oscillates around $280 \mathrm{DU}$ for the month of June and 265 DU for the month of July, a value which is far below the measured value above Lampedusa, which evolves within the 300-360 DU range for the entire simulation period (Fig. 3). Total ozone is routinely measured at Lampedusa by means of a MKIII Brewer spectrophotometer, as described in Meloni et al. (2005). According to the most up-to-date measurement values from Ziemke et al. (2011) (their Fig. 9b) for the area of Lampedusa, the climatological values for the stratospheric ozone column should be of 280 DU for June and 260 DU for July at Lampedusa, much stronger than the McPeters et al. (1997) values used in the present study (respectively 248.6 and 236.4 DU for June and July). Therefore, the low bias of about $30 \mathrm{DU}$ in our total ozone columns relative to observed values can be attributed mostly or entirely to the use of the climatology used in the present study for stratospheric ozone values. This insufficient stratospheric ozone column is expected to have a significant impact on the modelled $J\left(\mathrm{O}^{1} \mathrm{D}\right)$ photolytic rates. It is already known by the Fast-JX developers ${ }^{4}$ that the Fast-JX climatol-

\footnotetext{
${ }^{4}$ M. Prather, personal communication, 2014
}

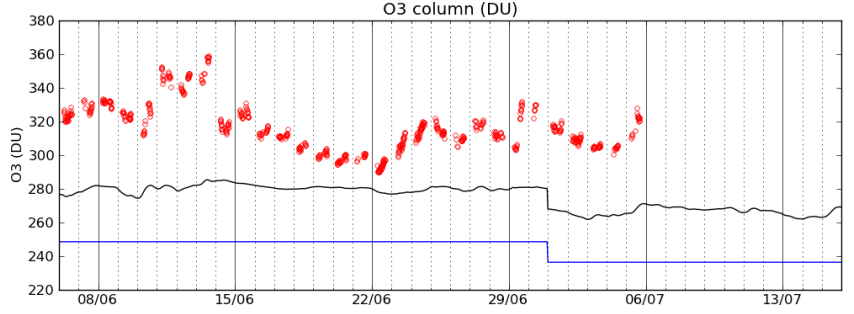

Figure 3. Modelled total (black line) and stratospheric (blue line) ozone column above Lampedusa, expressed in Dobson units (DU), compared to the measured values (red circles).

Table 2. Refractive indices used for mineral dust.

\begin{tabular}{cc}
\hline$\lambda(\mathrm{nm})$ & Refractive index \\
\hline 200 & $1.53+5.5 \times 10^{-3} i$ \\
300 & $1.53+5.5 \times 10^{-3} i$ \\
400 & $1.53+2.4 \times 10^{-3} i$ \\
600 & $1.53+8.9 \times 10^{-4} i$ \\
1000 & $1.53+7.4 \times 10^{-4} i$ \\
\hline
\end{tabular}

ogy based on McPeters et al. (1997) may need an update in subsequent versions of the Fast-JX model.

Figure 3 also shows that the variability of the total ozone column is much smaller in the model than in the observed values, most likely also due to the use of climatological stratospheric ozone columns, because the observed extreme variations of the ozone column (from 360 to $290 \mathrm{DU}$ ) are too strong to be due to the variability of the tropospheric ozone column alone. In fact, the ozone column simulated by CHIMERE from the ground to $300 \mathrm{hPa}$ varies around $25 \mathrm{DU}$, with relatively small variations. This value of tropospheric ozone column is smaller than climatological value from the Ziemke et al. (2011) results, which is around 40 DU for JuneJuly in the Lampedusa area, but this is consistent with the fact that the atmospheric layer from the ground to $300 \mathrm{hPa}$ simulated by CHIMERE does not include the ozone-rich layers of the upper troposphere.

As it is well known that the total ozone column is a critical parameter in simulating accurately the value of $J\left(\mathrm{O}^{1} \mathrm{D}\right)$ in the troposphere, we performed a sensitivity simulation (which we will refer to as $\mathrm{O} 3+$ ) identical to the REF simulation except that the calculation of the photolytic rates has been performed after multiplying the ozone concentrations throughout the stratosphere and the troposphere by 1.18 , thereby compensating the bias on ozone column visible in Fig. 3.

\subsection{The back-plume calculation methodology}

In order to understand the origin of several air masses, a simplified back-plume model was developed and used in this study. The main principle is to use the WRF simulation re- 
sults and to advect back in time numerous passive tracers. For each back plume, a location, a time and an altitude are chosen for the tracer release. The meteorological parameters used are

- the three-dimensional wind components: $u$ the zonal wind $\left(\mathrm{m} \mathrm{s}^{-1}\right), v$ the meridian wind $\left(\mathrm{m} \mathrm{s}^{-1}\right)$ and $w$ the vertical wind $\left(\mathrm{m} \mathrm{s}^{-1}\right)$;

- the boundary layer height $\bar{h}$ and the surface sensible heat flux $Q_{0}$.

For each starting point, 100 passive tracers are launched. For each one, its back trajectories are estimated during the previous $120 \mathrm{~h}$, back in time. Three cases are considered for each time and each location.

- In the boundary layer and during a convective period $\left(Q_{0}>0\right)$, we consider that the particle is in the convective boundary layer. The meteorological fields being available at an hourly time step, we consider the particle may have been at any level inside the boundary layer the hour before. We thus apply a random function to reproduce vertical mixing within the boundary layer.

- In the boundary layer and during a stable period $\left(Q_{0}<\right.$ 0 ), the particle stays in the boundary layer at the same altitude.

- In the free troposphere, we consider that the particle vertical evolution may be influenced by the vertical wind component. We thus apply a random function to estimate its possible vertical motion with values between $w / 2$ and $3 w / 2$.

Particles launched at the same initial position can have distinct evolutions back in time; therefore, the initial sample of 100 particles have distinct back trajectories depending on their random vertical movements inside the convective boundary layer and their partly random vertical movements within the free troposphere. Even though this back-plume model is possibly not comparable to state-of-the-art models such as HYSPLIT or FLEXPART, this model has been chosen for its simplicity of use in a study in which back trajectories are not a critical part. It does not necessarily imply that such a simplified formulation would be adequate for studies in which accuracy of the back-plume simulations is critical.

\subsection{Observational data and techniques}

The Lampedusa station is located on the Lampedusa island. Lampedusa is a small island located some $140 \mathrm{~km}$ east of the Tunisian coast and about $210 \mathrm{~km}$ south-west of the Sicilian coast, so that the aerosol properties at and above Lampedusa can be considered as mainly representative of longrange transport and of marine aerosol (Pace et al., 2006). The measurements available at Lampedusa during the simulated period or at least during part of it include measurements by the MFRSR instrument (multifilter rotating shadowband radiometer) for the aerosol optical depth, a Metcon diode array spectrometer for actinic flux and photolytic rates, a Brewer spectroradiometer for total ozone column, an aerosol LIDAR and a low-volume dual-channel sequential sampler.

\subsubsection{Remote sensing and radiative measurements}

The AERONET (http://aeronet.gsfc.nasa.gov) and MFRSR data were used for the AOD. MFRSR data were also used for calculating $J\left(\mathrm{NO}_{2}\right)$ and $J\left(\mathrm{O}^{1} \mathrm{D}\right)$ at the Lampedusa supersite. The AERONET data were used for three stations: Lampedusa $\left(35.51^{\circ} \mathrm{N} ; 12.63^{\circ} \mathrm{E}\right)$, Oujda $\left(34.65^{\circ} \mathrm{N} ; 1.90^{\circ} \mathrm{E}\right)$ and Palma de Mallorca $\left(39.55^{\circ} \mathrm{N} ; 2.63^{\circ} \mathrm{E}\right)$. Level 2.0 data were used for Oujda and Palma de Mallorca, while only Level 1.5 data were available for Lampedusa. The AOD time series for Lampedusa were completed by MFRSR measurements carried out at the Lampedusa station (Pace et al., 2006; di Sarra et al., 2015) for the periods when the AERONET data were not available, namely 6 to 16 and 27 June. It was shown in di Sarra et al. (2015) that the mean bias of the MFRSR AOD relative to the AERONET measurements is always smaller than 0.004 for long-term series (1999-2013), with a $r^{2}$ correlation coefficient always above 0.97 at all wavelengths between the AERONET and the MFRSR measurements. The very good correspondence between both time series makes it possible to use the MFRSR measurements to complete the AERONET time series, as done in the present study. The AERONET AOD as well as MFRSR AOD has been interpolated at the wavelength of $400 \mathrm{~nm}$, which is one of the five wavelengths for which Fast-JX computes the AOD. The interpolation was performed following an Angström power law based on the nearest available wavelengths in the measured data: 380 and $440 \mathrm{~nm}$ for the AERONET data and 416 and $440.6 \mathrm{~nm}$ for the MFRSR data.

Actinic flux spectra were measured using a Metcon diode array spectrometer (Casasanta et al., 2011). The actinic flux measurements were calibrated at the beginning of SOP1a by using NIST traceable 1000 watt lamps. The value of $J\left(\mathrm{O}^{1} \mathrm{D}\right)$ was derived from the actinic flux measurements as described by Casasanta et al. (2011). $J\left(\mathrm{NO}_{2}\right)$ was calculated from the measured actinic flux spectra by using the temperature dependent $\mathrm{NO}_{2}$ absorption cross sections by Davidson et al. (1988) and the $\mathrm{NO}_{2}$ quantum yield from Gardner et al. (1987). It is worth noting that the measured actinic flux, and therefore the photolysis rates, takes into account only the downward actinic flux.

The estimated accuracy is about 0.01 for the AERONET AOD, about 0.02 for the MFRSR AOD (Pace et al., 2006) and about $1 \%$ for the total ozone measurements by the Brewer spectroradiometer, which are done routinely at Lampedusa. The estimated uncertainty is between 5 and $8 \%$ for $J\left(\mathrm{O}^{1} \mathrm{D}\right)$, depending on the solar zenith angle and occurring conditions, and about $3-4 \%$ for $J\left(\mathrm{NO}_{2}\right)$. 
An aerosol LIDAR is operational at Lampedusa and provides measurements of vertical profiles of the aerosol backscattering at $532 \mathrm{~nm}$. Details on the instrumental setup and on the retrieval method are given by Di Iorio et al. (2009). For this study, one or two daily backscattering profiles, obtained by averaging LIDAR signal over 5-30 min intervals, are chosen as representative for the occurring conditions on the corresponding day. The vertical resolution of the measurements is $7.5 \mathrm{~m}$.

The AOD from MODIS Aqua and Terra v. 5.1 at $550 \mathrm{~nm}$ has been retrieved using the NASA LADS website ${ }^{5}$. Only quality-assured, cloud-screened level 2 data have been used for this study. The expected error envelope for these values is $\pm 0.05+0.15$ AOD over land and $\pm 0.03+0.05$ AOD over ocean. About $60 \%$ of values (above ocean) and $72 \%$ (over land) fall within this expected error margin (Remer et al., 2008). When available, we use in priority the AOD from the deep-blue algorithm, which permits us to have satelliteretrieved values for the AOD even over bright surfaces such as desert areas. This product has an expected error envelope of $\pm 0.03+0.20$ AOD (Sayer et al., 2013).

\subsubsection{Aerosol concentration and speciation}

$\mathrm{PM}_{10}$ samples were collected at Lampedusa Island at $12 \mathrm{~h}$ resolution by using a low-volume dual-channel sequential sampler (HYDRA FAI Instruments) equipped with sampling heads operating in accord with the European standard EN 12341 (following directive 2008/50/EC on ambient air quality and cleaner air for Europe). The mass of $\mathrm{PM}_{10}$ was determined by weighting the filters before and after the sampling with an analytical balance in controlled conditions of temperature $\left(20 \pm 1{ }^{\circ} \mathrm{C}\right)$ and relative humidity $(50 \pm 5 \%)$. The estimated error on the basis of balance tolerance for the $\mathrm{PM}_{10}$ mass is around $1 \%$ at $30 \mu \mathrm{g} \mathrm{m}^{-3}$ of $\mathrm{PM}_{10}$ in the applied sampling conditions. A quarter of each filter is analysed for soluble ions content by ion chromatography as described in Marconi et al. (2014). The error margin for ion chromatographic measurements is of $5 \%$ for all the considered ions.

$\mathrm{Na}, \mathrm{Cl}, \mathrm{Mg}, \mathrm{Ca}, \mathrm{K}$ and sulfate are the main components of sea-salt aerosol (SSA). As these ions (excluding $\mathrm{Cl}$ ) have sources other than sea spray, the sea-salt fraction of each ion was used to SSA calculation. Details on the calculation of sea-salt and non-sea-salt fraction for $\mathrm{Na}$ and $\mathrm{Ca}$ by using the ratio $\mathrm{Ca} / \mathrm{Na}$ in sea water $\left((\mathrm{Ca} / \mathrm{Na})_{\mathrm{sw}}=0.038\right.$; Bowen, 1979 ) and $\mathrm{Na} / \mathrm{Ca}$ average in the upper continental crust $\left((\mathrm{Ca} / \mathrm{Na})_{\mathrm{ucc}}=0.56\right.$; Bowen, 1979) $)$ are reported in Marconi et al. (2014). The sea-salt fractions for $\mathrm{Mg}, \mathrm{Ca}, \mathrm{K}$ and sulfate are calculated by multiplying the sea-salt $\mathrm{Na}$ by the ratio of each component in bulk sea water: $(\mathrm{Mg} / \mathrm{Na})_{\mathrm{sw}}=0.129$, $(\mathrm{Ca} / \mathrm{Na})_{\text {sw }}=0.038,(\mathrm{~K} / \mathrm{Na})_{\text {sw }}=0.036,\left(\mathrm{SO}_{4}^{2-} / \mathrm{Na}\right)_{\text {sw. }}=$ 0.253 . For chloride we used the measured concentration instead of the calculation from sea-salt $\mathrm{Na}$, because during the

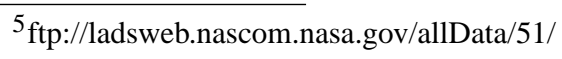

aging of sea spray chloride undergoes a depletion process (Keene et al., 1998), mainly due to reactions with anthropogenic $\mathrm{H}_{2} \mathrm{SO}_{4}$ and $\mathrm{HNO}_{3}$, leading to re-emission of $\mathrm{HCl}$ in the atmosphere. Previous work by Kishcha et al. (2011) shows a very good agreement between SSA obtained by DREAM-Salt model and the calculated SSA from chemical composition at Lampedusa.

Dust aerosol is calculated from non-sea-salt $\mathrm{Ca}$ as this marker is one of the most reliable of crustal material (Putaud et al., 2004; Sciare et al., 2005; Guinot et al., 2007; Favez et al., 2008). Besides, Ca is largely used because it allows the identification and quantification of Saharan dust on the basis of only ion chromatographic measurements. However, upper continental crust presents a large variability in Ca content. In particular, some areas of the Sahara are enriched in Ca minerals (Scheuvens et al., 2013), leading to an overestimation of crustal material in the aerosol by using only the $\mathrm{Ca}$ (or nonsea-salt $\mathrm{Ca}$ ) in the calculation. In the Mediterranean region, several studies have evaluated and used calcium-to-dust conversion factors to estimate the crustal content (Sciare et al., 2005; Favez et al., 2008). In Lampedusa, over an extensive data set, Marconi et al. (2014) found a significant correlation between non-sea-salt $\mathrm{Ca}$ and crustal content computed by the more reliable method of the main crustal element oxides formula. The slope of the regression line $(10.0 \pm 2 \%)$, which is in the range of previous studies in the Mediterranean region (Sciare et al., 2005; Favez et al., 2008), is used as calcium-todust conversion factor in the present study. Finally, non-dust $\mathrm{PM}_{10}$ is obtained by subtraction of dust content from $\mathrm{PM}_{10}$ total mass.

\section{Results}

\subsection{Representation of the aerosols in the model: comparison to observations}

\subsubsection{Aerosol optical depth and radiative indices}

Figure 4 compares the AOD simulated by CHIMERE at $550 \mathrm{~nm}$ (interpolated from the simulated values at 400 and $600 \mathrm{~nm}$ following an Angström power law) to that measured by MODIS at $550 \mathrm{~nm}$, averaged from 6 June to 15 July. On some parts of the domain, the MODIS averages can be built from 30 to 40 measured values, representing data availability in excess of $75 \%$ (Fig. 5). This is the case above the Mediterranean sea and the surrounding continental areas with maxima of data availability on the coasts of the Mediterranean Sea, from Morocco to Turkey. On the contrary, data availability is poor (less than 5 values available over the 40-day simulation period) for many zones, including the Intertropical Convergence Zone, around $5^{\circ} \mathrm{N}$, the Arabian peninsula, the southern parts of Libya and Egypt and the north-east Atlantic. Comparison of the CHIMERE and MODIS mean values (Fig. 4) shows that, on average for the entire considered 

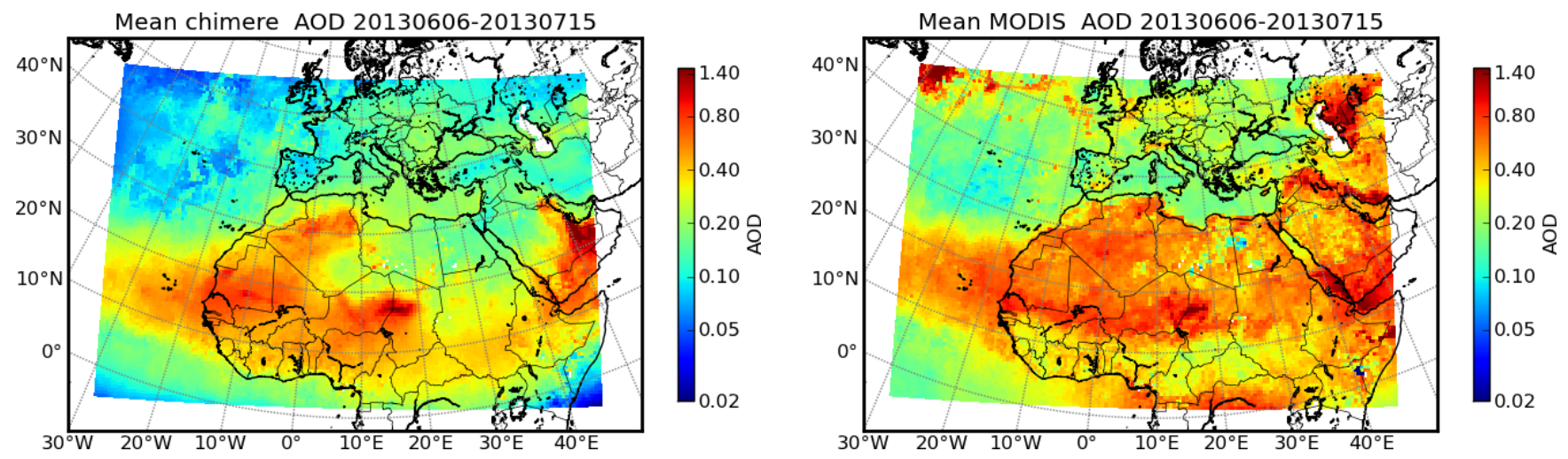

Figure 4. AOD at $550 \mathrm{~nm}$ in the CHIMERE model (left column) and as observed by MODIS AQUA and TERRA, averaged from 6 June to 15 July 2013. Only the points where MODIS data are available are taken into account in the averaging procedure for the CHIMERE data.

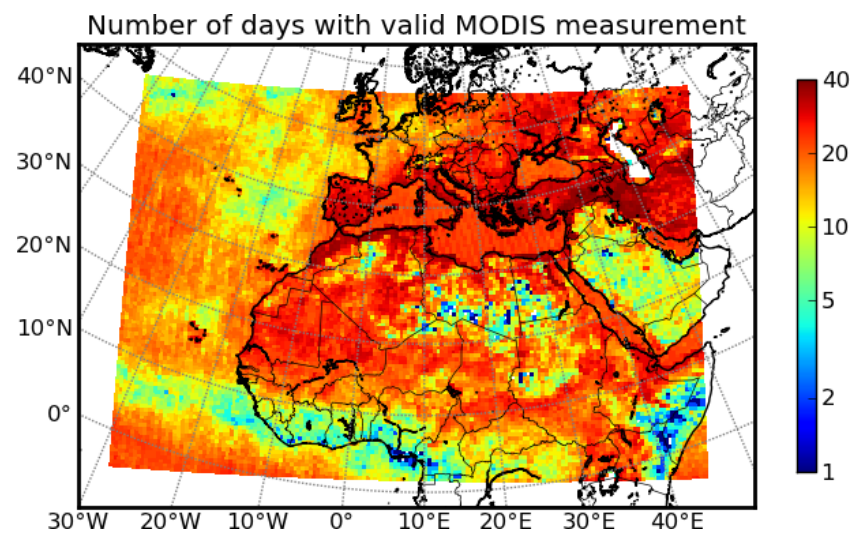

Figure 5. Number of days with available MODIS measurements between 6 June and 15 July.

period, CHIMERE realistically reproduces the main features of the AOD over the considered region, with average values above unity for the Sahelian band and the Arabian peninsula. However, CHIMERE misses high AOD values on the eastern side of the Caspian Sea as well as over the northern part of the Atlantic and also underestimates the AOD in eastern Sahara. For the first area, the underestimation of the AOD by CHIMERE may be related to missing dust emissions, while for the northern Atlantic the high AOD values in MODIS are related to an average computed from very few data points (Fig. 5), possibly during an event of transport of an aerosol plume (e.g. biomass burning or mineral dust) from outside the simulation domain, or contaminated by the presence of thin clouds in that area.

For the most important part of our domain, including continental Africa, the comparison of the average AOD between CHIMERE and MODIS is rather satisfactory: maxima due to local dust emissions are observed in the Sahara and Sahel, and the climatological dust plume off the coast of West Africa and above the Capo Verde islands is well captured by the model, even though some underestimation in the model can be seen in this plume.

Over the Mediterranean Sea, average values around 0.2 are modelled by CHIMERE and observed by MODIS, with larger values just off the coasts of North Africa and a southnorth gradient, with smaller AOD values in the northern part of the Mediterranean sea.

Regarding the time evolution of the AOD, we selected 3 particular days in June: 17, 19 and 21 June, sampling the dust outbreak that occurred between 13 and 25 June over the western Mediterranean basin, during ADRIMED SOP1a. Figure 6 shows the AOD at $400 \mathrm{~nm}$ and at 12:00 GMT simulated by CHIMERE for these 3 days and measured by MODIS for the same dates (MODIS overpass was between 10:00 and 14:00 GMT over the considered zones for these days).

For 17 June (Fig. 6a-b), the dust plume is visible over the Mediterranean both in the model and in observations, with maximal AOD values around 0.6 in both cases, even though the plume seems slightly more extended and optically thicker in the model than in the observations. In both model and observations, the maximal AOD for this plume is located over the sea, south-west of the Balearic islands. For 19 June (Fig. 6c-d), the dust plume has moved to the east, just west of Corsica and Sardinia. It extends further to the south in the model than in observations. Finally, on 21 June (Fig. 6e$\mathrm{f}$ ), the dust plume is over the Tyrrhenian Sea, also reaching Lampedusa, and has become significantly more intense in the model than in observations.

During the same time period, a zone of strong AOD is present in CHIMERE off the coasts of France, Britain and Ireland (Fig. 6a) and then over the Gulf of Gascony (Fig. 6c); finally, on 21 June, a zone of very strong AOD is present over the North Sea. No MODIS measurements are present at the same time to evaluate this zone of high aerosol loads, even though Fig. 6d indicates a zone of relatively strong AOD over the North Sea at that time (19 June), consistent with CHIMERE simulation. 

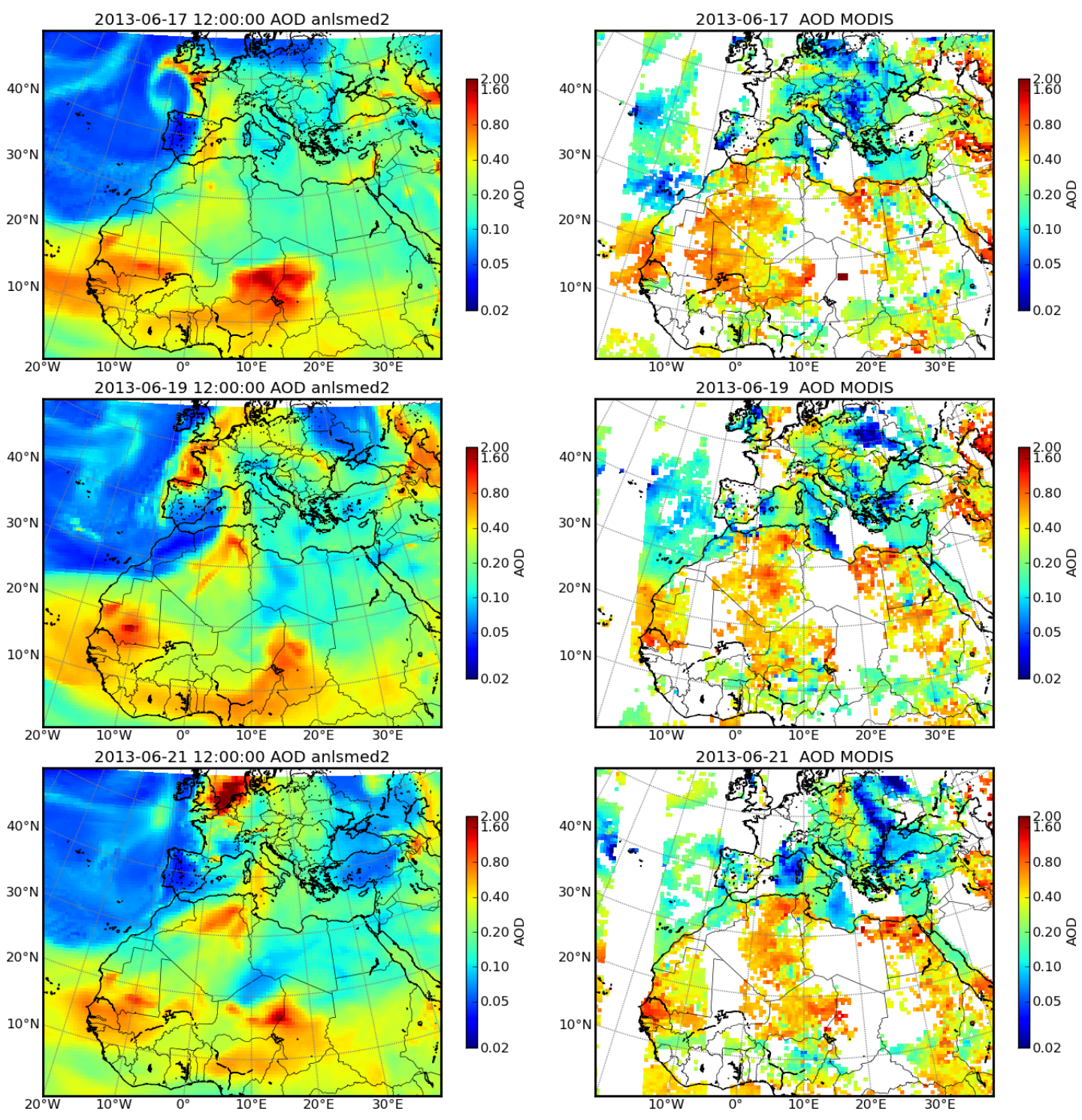

Figure 6. AOD at $550 \mathrm{~nm}$ in the CHIMERE model (left column) and as observed by MODIS AQUA and TERRA for 17, 19 and 21 June 2013.

A detailed comparison of the AOD with AERONET stations for all the ADRIMED period is presented in Menut et al. (2015a). In the present study, we selected three AERONET stations that have sampled the dust plume we discussed before in order to evaluate the modelled AOD for the considered period.

These three AERONET stations have been selected in the western Mediterranean according to the data availability for June 2013 and their position on the trajectory of the dust plume of 13-25 June as seen by MODIS. As discussed in Sect. 2, the three selected stations are Lampedusa (Italy), Oujda (Morocco) and Palma de Mallorca (Spain). The AERONET data for Lampedusa were not available for 1 to 16 June, so that the time series have been completed using the MFRSR data at Lampedusa station for those 16 days as well as for 27 June. The comparison of the AOD measured in these three AERONET stations to the AOD of CHIMERE is shown in Fig. 7 at $400 \mathrm{~nm}$. Statistical scores have also been calculated for 10 additional AERONET stations from the Saharan area to northern Europe (Table 3).

The dust peak observed from 21 to 24 June in Lampedusa is simulated realistically by CHIMERE (Fig. 7a). The peak value of the AOD is about 0.5 in the model and 0.35 in the observations. Three other sharp peaks in AOD are represented in CHIMERE for 6, 9-10 June and 2-4 July. The peak of 6 June is the most intense in the simulation period and has a rather short duration (about $24 \mathrm{~h}$ ). The maximal value of the AOD during this peak is between 0.8 and 0.9 in both the MFRSR data and the model in the afternoon of 6 June. The AOD value then steadily decreases on 7 June, ranging be- 
Table 3. Statistical scores for comparison of modelled AOD values at $400 \mathrm{~nm}$ (from the REF simulation) and observed ones, from AERONET network data (completed when necessary by the MFRSR data in the case of Lampedusa). For each station, the following data are given: name and geographical coordinates of the station, number of hourly values $\left(N_{\text {hour }}\right)$, mean value and standard deviation $(\sigma)$ of observed and modelled data, correlation coefficient $R$ and two-sided $p$ value for a zero hypothesis with null slope.

\begin{tabular}{lrr|rr|rr|r|r|r|r|r}
\hline Name & Lat & Long & \multicolumn{2}{|c|}{$N_{\text {hour }}$} & \multicolumn{2}{|c|}{ Mean } & Bias & \multicolumn{2}{c}{$\sigma$} & \multicolumn{2}{c}{$R$} \\
& & & OBS & MOD & OBS & MOD & & OBS & MOD & \\
\hline Lampedusa & 35.52 & 12.63 & 370 & 961 & 0.21 & 0.25 & 19.08 & 0.11 & 0.11 & 0.8 & $9.7 \mathrm{e}-83$ \\
Palma_de_Mallorca & 39.55 & 2.63 & 440 & 961 & 0.21 & 0.18 & -11.24 & 0.1 & 0.08 & 0.18 & 0.00011 \\
Oujda & 34.65 & -1.9 & 377 & 961 & 0.23 & 0.21 & -9.9 & 0.1 & 0.1 & 0.64 & $2 \mathrm{e}-45$ \\
Cap_d_en_Font & 39.82 & 4.2 & 258 & 961 & 0.22 & 0.16 & -25.12 & 0.11 & 0.08 & -0.14 & 0.022 \\
Gozo & 36.03 & 14.25 & 461 & 961 & 0.23 & 0.25 & 8.3 & 0.1 & 0.1 & 0.4 & $5.2 \mathrm{e}-19$ \\
Murcia & 38.0 & -1.17 & 460 & 961 & 0.25 & 0.16 & -34.23 & 0.12 & 0.09 & 0.36 & $1.2 \mathrm{e}-15$ \\
Malaga & 36.72 & -4.48 & 439 & 961 & 0.22 & 0.18 & -16.94 & 0.11 & 0.11 & 0.71 & $3.1 \mathrm{e}-68$ \\
Potenza & 40.6 & 15.71 & 339 & 961 & 0.21 & 0.19 & -9.83 & 0.09 & 0.08 & 0.09 & 0.098 \\
Tamanrasset_INM & 22.78 & -5.52 & 412 & 961 & 0.38 & 0.43 & 15.09 & 0.18 & 0.24 & 0.38 & $8 \mathrm{e}-16$ \\
Tizi_Ouzou & 36.7 & 4.05 & 227 & 961 & 0.3 & 0.22 & -24.63 & 0.12 & 0.15 & 0.51 & $2.1 \mathrm{e}-16$ \\
Palaiseau & 48.7 & 2.2 & 202 & 961 & 0.36 & 0.14 & -61.49 & 0.19 & 0.07 & 0.03 & 0.67 \\
Mainz & 50.0 & 8.3 & 250 & 961 & 0.32 & 0.18 & -44.95 & 0.17 & 0.11 & 0.05 & 0.39 \\
\hline
\end{tabular}

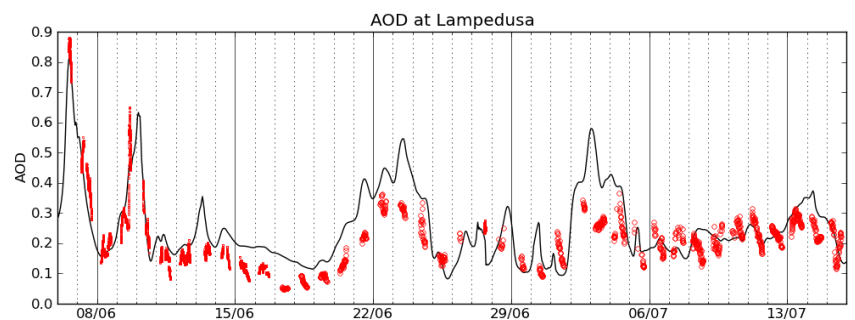

(a)

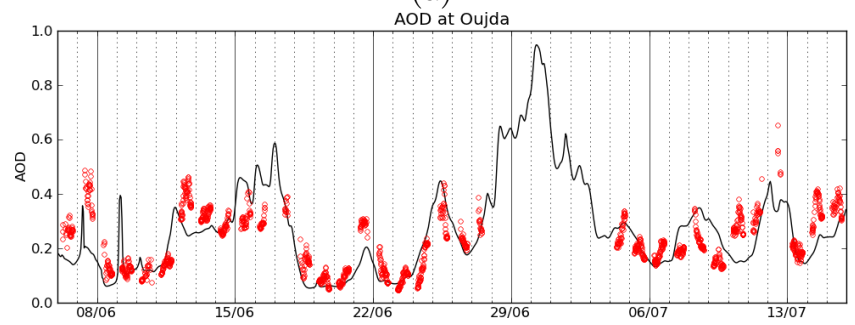

(b)

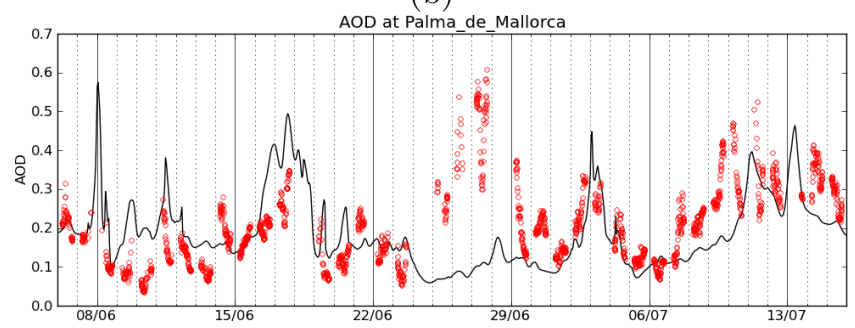

(c)

Figure 7. Evolution of modelled AOD (black lines) at $400 \mathrm{~nm}$ above Lampedusa, Oujda and Palma de Mallorca compared to the AERONET AOD interpolated at $400 \mathrm{~nm}$ (red circles). For Lampedusa, AERONET data are completed with MFRSR data (red dots) when the AERONET data were not available. tween 0.5 and 0.3 in both modelled and measured values for that day. The peak in the afternoon of 9 June, the second most intense in the whole data series $(\mathrm{AOD}=0.6)$ has been sampled by MFRSR and is present as well in CHIMERE, with a very comparable peak value reached in the afternoon of 9 June and the following night. The decrease of the AOD values occurs on 10 June, when AOD returns to a value of about 0.2. A last peak in AOD is present in both model and observations from 2 to 4 July, followed by moderate AOD values, around 0.2 , throughout the rest of the simulation period. For the entire simulation period at Lampedusa, the correlation coefficient between simulated and observed values is of 0.8 , while the bias of the model compared to the observations is of $19 \%$ (Table 3).

For the Oujda station (Fig. 7b), a period of strong AOD is represented in both the model and observations from 12 to 17 June, with a similar timing and duration between the model and the observations and a stronger value for the maximal AOD in the model than in observations (0.6 vs. 0.4). Another strong AOD peak is simulated by CHIMERE from 28 June to 2 July but with no available data at the time, and a last AOD peak is modelled and observed on 11-12 July. The background value of the AOD (about 0.05-0.1) for this location is represented realistically by CHIMERE. For this station, and for the entire simulation period, the correlation coefficient between the simulated and observed values is of 0.64 , with a negative bias of $-9.9 \%$ of the observed values relative to the simulated ones (Table 3).

Finally, for the Palma de Mallorca station (Fig. 7c), a very brief peak in AOD is simulated in CHIMERE for 7 June, but it is not seen in the AERONET time series because it occurs in nighttime. Thereafter, a peak from 16 to 18 June with AOD reaching 0.5 in CHIMERE and 0.3 AERONET is simulated and observed. A significant AOD peak from 25 to 30 June 
is observed but missed by the model. This event has been studied by Ancellet et al. (2015): using observational data and backward trajectories of the air masses, these authors attribute this period of strong aerosol load over the Balearic islands and other areas in the western Mediterranean to verylong range transport of forest fire smoke from North America as well as Saharan dust that came back into this area from the north-western tropical Atlantic. Therefore, the fact that the model misses this peak can be attributed to the fact that the aerosols causing this AOD peak originate from areas outside the simulation domain. A last AOD peak is simulated and observed on 2-3 July, and a trend towards higher AOD values can be seen in both the model and observations towards the end of the period. Contrary to Oujda and Lampedusa, the model behaviour is, however, globally not satisfactory at Palma de Mallorca, with a correlation coefficient of only 0.18 between simulated and observed AOD values (Table 3).

By briefly examining the statistical scores of the model for the 12 stations that have been selected for the statistical analysis in Table 3, several observations can be made. Regarding the average AOD bias, it is generally moderate for the 10 first stations of the list, in Africa and the Mediterranean basin (from -35 to $+19 \%$ ), but not for the two stations of Mainz (Germany) and Palaiseau (France) in continental Europe ( -61 and $-45 \%$ respectively). This confirms the observation made above from comparison with satellite data that the model has problems reproducing the relatively high AOD values that are observed over continental Europe. The same is true for the time evolution of the AOD: while the correlation coefficients for all the stations in Africa and the Mediterranean basin are significant at $99 \%$ except for the stations of Potenza (Italy) and Cap d'En Font (Baleares), the simulated AOD values have no correlation to the observations at the stations of Palaiseau and Mainz.

Inversion of the AERONET data also permits us to produce estimated values for the effective real and imaginary part of the refraction indices averaged over all the aerosol column (Dubovik et al., 2000). For the station of Lampedusa, we compared these measured values to the values used by CHIMERE (Table 2) for 6 days corresponding to dust intrusions that are observed by AERONET and simulated by CHIMERE: 22-24 June and 2-4 July. The result of this comparison is shown in Fig. 8. The values assumed for dust particles in Fast-J are at the limit of the range of variability of the inverted values for the real and imaginary part of the indices. It is worth noting that the uncertainty on the AERONET values for the refractive index is much stronger than the interval between the minimum and maximum of measured values: Dubovik et al. (2000) mention that a typical error of $1^{\circ}$ in the pointing of the photometer leads to errors up to 0.08 in the real part of the indices (if the true value is 1.53) and 0.004 on the imaginary part (if the true value is 0.008 ). This very large sensitivity to pointing errors is due to the fact that, due to their large diameter, the measurements of refractive indices for dust particles rely strongly on data from the solar aureole, which are particularly sensitive to pointing errors. Therefore, the assumed value lies within the uncertainty range of the AERONET values, understood as the sum of the variability of the measured values and their possible biases due to pointing errors.

All in all, it can be seen that the AOD values simulated by CHIMERE over the western Mediterranean and the Sahara compare well to observations from MODIS, AERONET and MFRSR, and the peaks simulated by CHIMERE during that period are generally observed except when they occur during nighttime, as it is the case for the night of 7-8 June in Palma de Mallorca. However, the AOD peak values during some AOD peaks are overestimated by up to $50 \%$ when compared to the observed values. Only one significant AOD peak is observed but missed by the model, from 25 to 30 June at Palma de Mallorca, while the model catches all the AOD peaks that occur at Lampedusa and Oujda during the simulation period. The longest dust transport event of this period (12-24 June) is represented realistically for all three locations, first in $\mathrm{Ou}-$ jda, thereafter in Palma de Mallorca, and finally at Lampedusa, even though for these three locations the peak value in AOD is stronger in CHIMERE than in the observations. Even though statistical analysis shows that the ability of the model to reproduce the observed AOD variation depends a lot on the location, and is not good over continental Europe, its performance is very satisfactory over Lampedusa, which was one of the ADRIMED SOP1a supersites, including measurements of both $J\left(\mathrm{O}^{1} \mathrm{D}\right)$ and $J\left(\mathrm{NO}_{2}\right)$. Therefore, it is possible to use the present simulations over the period of time from 6 June to 15 July 2013 to examine the impact of aerosol screening on photochemistry, taking advantage of the availability of measurements from the ADRIMED SOP1a period.

\subsubsection{Vertical structure}

The episodes of dust incursion visible on the simulated AOD time series (Fig. 7a) can also be seen in the time-altitude plots of the simulated particle concentrations: see Fig. 9a for coarse particles $\left(\mathrm{PM}_{10}-\mathrm{PM}_{2.5}\right)$ and Fig. $9 \mathrm{~b}$ for fine particles $\left(\mathrm{PM}_{2.5}\right)$. Dust is present above Lampedusa in the simulation outputs from 4 to 10 June, from 19 to 28 June, from 1 to 4 July and from 11 to 15 July (Fig. 9a). A significant amount of finer particles is also present in the boundary layer during most of the simulation period, particularly from 11 to 20 June, while maxima of $\mathrm{PM}_{2.5}$ concentration occur in the free troposphere as well during the dust outbreaks. LIDAR profiles have been selected once or twice a day for comparison to the model (Fig. 9c). In these LIDAR measurements of aerosol backscatter coefficient, aerosol plumes in the free troposphere are clearly visible from 8 to 10 June, from 19 to 28 June and from 2 to 4 July. These aerosol plumes in the troposphere are seen between 2000 and $6000 \mathrm{~m}$ altitude, consistent with the altitudes of the $\mathrm{PM}_{10}$ maxima simulated in CHIMERE. The first event sampled in the LIDAR data, between 8 and 10 June, occurs at a low altitude, with a con- 


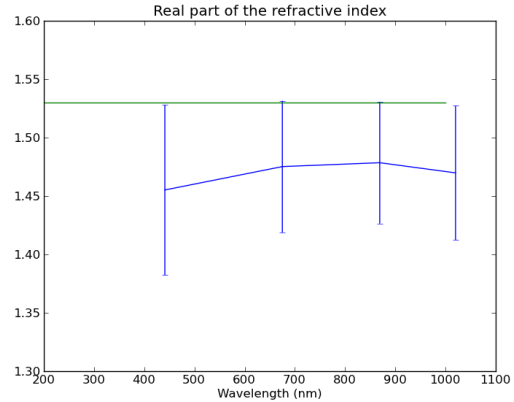

(a)

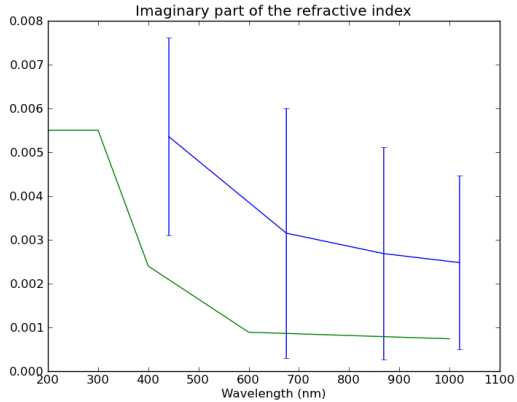

(b)

Figure 8. (a) Real part of the refractive index inverted from the AERONET measurements averaged for 22-24 June and 2-4 July (blue line: average and extreme of the 29 available hourly AERONET values) and value used by CHIMERE (green line). The blue error bars indicate the extreme values measured by AERONET during these 6 days. (b) Same as (a) but for the imaginary part of the refractive index.

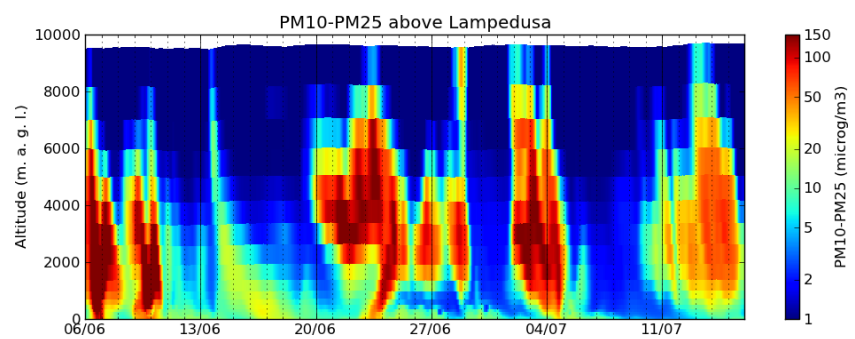

(a)

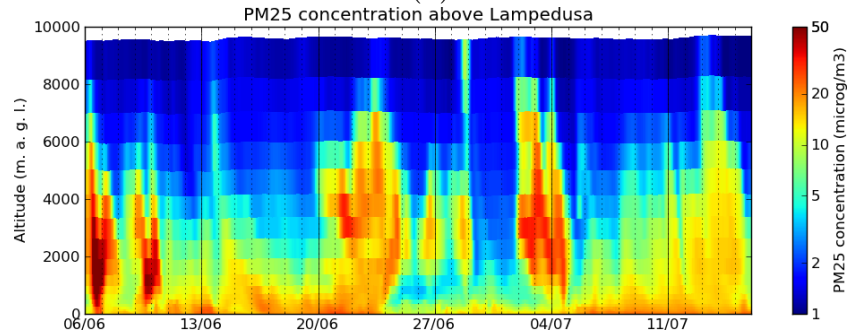

(b)

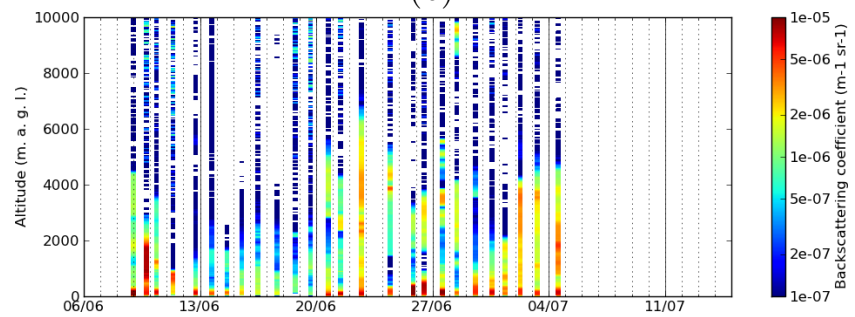

(c)

Figure 9. (a) Evolution of modelled coarse particles concentrations $\left(\mathrm{PM}_{10}-\mathrm{PM}_{2.5}\right)$ above Lampedusa; (b) same as (a) but for the fine particles $\left(\mathrm{PM}_{2.5}\right)$; (c) LIDAR backscatter coefficient above Lampedusa. Each selected LIDAR profile is represented by a column of fixed width centred on the instant of the measurement, representing the backscatter coefficient (colour levels).

centration maximum between 1000 and $2000 \mathrm{~m}$ a.g.l in both measurements and simulation. During the same period, a strong backscatter signal is also observed in the boundary

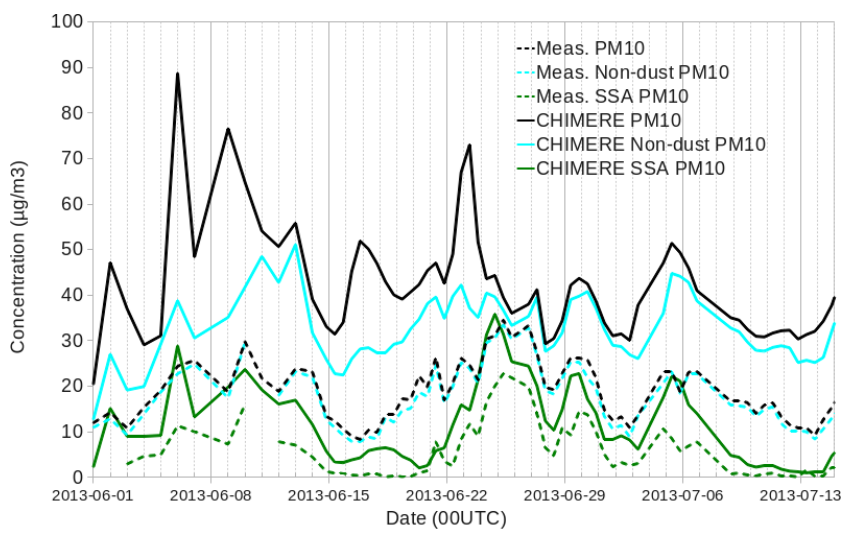

Figure 10. Modelled speciation of $\mathrm{PM}_{10}$ aerosols in the first model layer compared to measurements for total $\mathrm{PM}_{10}$ (black lines), nondust $\mathrm{PM}_{10}$ (blue lines) and sea-salt aerosols (green lines).

layer, corresponding to the maxima of fine particle concentrations in the boundary layer. This boundary-layer contribution is dominant when there is no significant contribution from dust in the free troposphere, which is the case from 11 to 19 June (Fig. 9b). Modelled profiles display a structure that is very similar to the observed one. However, it must be pointed out that the modelled dust plume reaches generally higher altitudes, up to about $8 \mathrm{~km}$, than observations.

\subsubsection{Speciation}

For the simulation period, the speciation of the particulate matter in the first model layer (Fig. 10) is shown. For the first model layer, a comparison of $\mathrm{PM}_{10}$ speciation has been performed between the model and the measurements, for three categories of aerosols: total $\mathrm{PM}_{10}$, non-dust $\mathrm{PM}_{10}$ and SSA $\mathrm{PM}_{10}$. It is worth noting that, even though the Lampedusa station is located at an altitude of $45 \mathrm{~m}$ a.s.l., we compared the measured concentrations to the concentrations modelled for the first modelled level $(0-30 \mathrm{~m})$ rather than the second 
model level (30-70 m). We lack small-scale meteorological information to know whether the air masses that arrive at the measurement station come from the first $30 \mathrm{~m}$ above the sea or from air particles that were already at about the altitude of $45 \mathrm{~m}$ during their travel above open sea. However, we checked that the modelled concentrations of the various aerosol species above Lampedusa do not change measurably between the first and the second model layer (not shown), so that the results discussed in the present study are not sensitive to that choice.

For total $\mathrm{PM}_{10}$ (black lines), the agreement between modelled and measured value is not good, with a large overestimation of aerosol concentration by CHIMERE (the average value for all the times where measured values are available is $41.9 \mu \mathrm{g} \mathrm{m}^{-3}$ in CHIMERE against $18.8 \mu \mathrm{g} \mathrm{m}^{-3}$ in the measurements), with a significant but moderate temporal correlation (correlation coefficient of 0.40). Results for non-dust $\mathrm{PM}_{10}$ (blue lines) are much better. Even though the bias in CHIMERE is still strong $\left(31.7 \mu \mathrm{g} \mathrm{m}^{-3}\right.$ in CHIMERE against $17.6 \mu \mathrm{g} \mathrm{m}^{-3}$ in the measurements), the temporal correlation $(R=0.72)$ is much stronger. The better agreement in nondust $\mathrm{PM}_{10}$ between the model and the measurements permits us to conclude that the poor agreement between model and observations for total $\mathrm{PM}_{10}$ is in part due to an overestimation of dust concentrations in the first model layer by CHIMERE. Given the vertical structure of the dust layers, which are essentially located in the free troposphere (Fig. 9), this large overestimation of dust concentrations at ground level in Lampedusa may be an indicator of excessive sedimentation (caused either by the sedimentation scheme or by a bias in the size distribution of aerosols), an excessive numerical diffusion in the model compared to reality or a misrepresentation of the marine boundary layer by the WRF model.

Examining the time series for sea-salt aerosols (Fig. 10, green lines), there is a very good temporal correlation between CHIMERE and the measured values $(R=0.90)$, showing that the evolution of the sea-salt concentration is very well captured by the model. However, a significant bias in modelled values relative to the observations can be observed due to the presence in the model of a significant background concentration of sea salt: while the modelled seasalt concentrations almost always exceed $5 \mu \mathrm{g} \mathrm{m}^{-3}$, the measured values get very close to 0 in some periods. Numerous causes for this overestimation of background sea-salt concentration in the model could be considered. This overestimation could be due to a misrepresentation of the low-level wind, to deficiencies in the sea-salt emission scheme (Monahan, 1986) or in the transport, scavenging and/or deposition of sea salt, as well as to possible misrepresentations of the marine boundary layer by the meteorological model. We are not able to conclude about this point in the present study. To summarise, simulated $\mathrm{PM}_{10}$ in the boundary layer is overestimated by $25 \mu \mathrm{g} \mathrm{m}^{-3}$ on average in the boundary layer at Lampedusa. This overestimation comes from the mineral

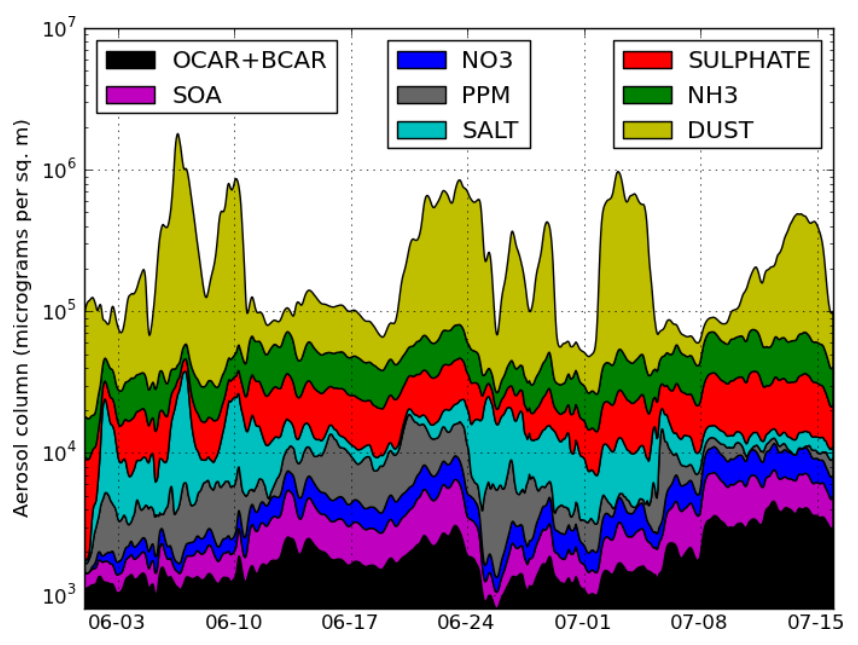

Figure 11. Cumulative plot of the total aerosol mass load $\left(\mu \mathrm{g} \mathrm{m}^{-2}\right)$ for the following groups of species: organic and black carbon (OCAR+BCAR), secondary organic aerosols (SOA), nitrates $\left(\mathrm{NO}_{3}\right)$, primary anthropogenic particulate matter (PPM), sea salt (SALT), sulfate, ammonium $\left(\mathrm{NH}_{3}\right)$ and mineral dust (DUST).

dust $\left(8 \mu \mathrm{g} \mathrm{m}^{-3}\right)$, the sea-spray aerosols $\left(5 \mu \mathrm{g} \mathrm{m}^{-3}\right)$ and other aerosols $\left(9.5 \mu \mathrm{g} \mathrm{m}^{-3}\right)$.

Regarding the total aerosol column (Fig. 11), it is generally largely dominated by dust, with dust loads reaching $1-$ $2 \mathrm{~g} \mathrm{~m}^{-2}$ during a sharp peak, and a background level around or below $0.1 \mathrm{~g} \mathrm{~m}^{-2}$. Therefore, mineral dust is the dominant contributor to the AOD for Lampedusa at least during AOD peaks. At Lampedusa, the other aerosol species contribute to the total aerosol column load by at least 1 order of magnitude less than mineral dust. This is the case of ammonium, sulfates, sea salts and primary anthropogenic particulate matter $\left(\simeq 0.01-0.1 \mathrm{~g} \mathrm{~m}^{-2}\right)$, while all the other species contribute again 1 order of magnitude less.

The LIDAR measurements in Fig. 9b, c show that the aerosols in the free troposphere, where dust is dominant (Fig. 11), seem to have a stronger contribution to the total backscatter than aerosols located in the boundary layer, where non-dust aerosols generally dominate (Fig. 10). In that sense, both model and measurements seem to indicate that the dominant contribution to the AOD during the considered period can be attributed to the presence of dust in the free troposphere, at least during periods of AOD peaks. The boundary-layer aerosols such as sea salt and other species might have a significant contribution to the background AOD values in periods when dust is almost absent from the troposphere above Lampedusa, as it is the case between 12 and 18 June for example.

Finally, in order to understand the source regions of the aerosols modelled and observed above Lampedusa, we performed a back-trajectory study for two particular times and altitudes (Fig. 12): 23 June, 12:00 UTC, at $4500 \mathrm{~m}$ altitude, selected inside a free-tropospheric dust layer (Fig. 9), and 
24 June, 12:00 UTC, at 10 m.a.g.l., a zone of strong sea-salt concentration in the marine boundary layer (Fig. 10). Figure 12a shows that the air masses arriving at $4500 \mathrm{~m}$ above Lampedusa on 23 June at 12:00 UTC were all located above North Africa from 72 to $24 \mathrm{~h}$ before their arrival. Over these arid areas where they stayed for several days being caught in the boundary layer every day and detrained every night (Fig. 12c), they gained a significant content in mineral dust particles likely due to local emissions. These dust particles are then advected to the vertical of Lampedusa, being in the free troposphere during the last $72 \mathrm{~h}$ of their travel. Looking at the back trajectories of the air masses contributing to the strong sea-salt content on 23 June at 12:00 UTC in the lowest layers (Fig. 10), the back trajectories (Figure 12b) show that these particles come from the north-west and have travelled $24 \mathrm{~h}$ or more above the western Mediterranean, most of them staying inside the marine boundary layer all along their trajectory (Fig. 12d). These trajectories are consistent with the back trajectories given by Pace et al. (2006) for days with a strong sea-salt content at Lampedusa, and they provide a particularly long trajectory of this air mass above water, which favours strong sea-salt content of these air masses (Granier et al., 2004).

As a summary of this section, the following can be concluded:

- The average AOD over most of the simulation domain is simulated correctly by CHIMERE for the considered time period (1 June to 15 July) and compares favourably to MODIS AOD.

- The dust plume simulated by CHIMERE over the western Mediterranean from 13 to 25 June is also captured by MODIS, as well as by the relevant AERONET stations. It has been observed by the LIDAR in Lampedusa at about the same time and altitude as modelled in CHIMERE. The AOD values simulated are realistic, as is the eastward movement of the plume and its timing at each of the measurement stations.

- At Lampedusa, measurements of the chemical composition of aerosols show that the dust plume has not reached the ground level during the simulation period, which is contrary to the simulation outputs. This overestimation of dust concentration in the boundary layer might be a consequence of excessive numerical diffusion in the model, as discussed in Vuolo et al. (2009).

\subsection{Impact of aerosols on photolysis rates at Lampedusa}

\subsubsection{Comparison of modelled $J\left(\mathrm{NO}_{2}\right)$ to observations}

Figure 13a shows the time series of the daily maxima of $J\left(\mathrm{NO}_{2}\right)$ in both simulations as well as the $J\left(\mathrm{NO}_{2}\right)$ value derived from the Metcon spectrometer measurements at Lampedusa. The measurements take into account only the downward contribution to the actinic flux, while the modelled value also includes the upward flux due to the non-zero albedo of the surface. Since the albedo of the surface in the model has been set to a fixed value of $A=0.1$ for this simulation, we multiplied the modelled value for $J\left(\mathrm{NO}_{2}\right)$ by a correction factor of $1 /(1+A)$ in order to obtain a modelled $J\left(\mathrm{NO}_{2}\right)$ value plotted in Fig. 13a, which is representative of the downward component of the actinic flux only and can therefore be compared directly to the measured values. It is worth noting that the simulation period is centred on the summer solstice, so that the solar zenith angle at local solar noon only varies from $12.89^{\circ}$ on 6 June to $12.07^{\circ}$ on 21 June. The cosine of that angle (which determines the optical path of incoming solar rays inside the atmosphere) only varies by about $0.3 \%$ during the measurement period. This explains the fact that no seasonal trend is visible either in the model or in the measurements, and it need not be taken into account for our study. Similarly, changes in the Sun-Earth distance are very small and produce a negligible effect on the dayto-day variations in the selected period. Thin clouds were present above the station on $6,7,8,10,11,13,14,24$ June and on 4 and 5 July. These days are signalled in Fig. 13a by empty diamonds, while days when no cloud influence exists in the measurements are represented by full diamonds. In the model, cloud cover was present over Lampedusa in daytime only on 27, 30 June and 5 July. However, it is visible in Fig. 13a-b that these clouds were not thick enough to influence the photolytic rates above Lampedusa.

Two observations can be made from Fig. 13a. First, the values of diurnal maxima of $J\left(\mathrm{NO}_{2}\right)$ in both simulations are positively biased. This bias is $12.3 \%$ for the simulation without aerosols (NA) and $8.2 \%$ in the reference simulation so that, in average during the simulation period, the direct radiative effect of the aerosol reduced the daily maxima of $J\left(\mathrm{NO}_{2}\right)$ by about $4 \%$. The second observation is that the variations of the daily maxima of $J\left(\mathrm{NO}_{2}\right)$ in the REF simulation correspond almost exactly to those of the measured data: calculating the linear correlation between these two time series yields a correlation coefficient of 0.92 and a slope of 1.13 (Table 4), both representing an excellent correlation between the simulated and measured daily maxima of $J\left(\mathrm{NO}_{2}\right)$. This excellent correlation indicates that the variations of $J\left(\mathrm{NO}_{2}\right)$ due to the optical effect of aerosols are very well represented in this simulation. Comparison between Figs. 13a and 7a shows that this effect is mostly substantial only when the AOD reaches or exceeds values around 0.2. This result 


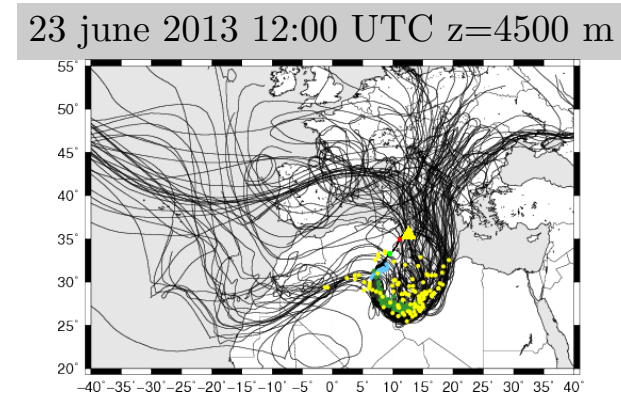

(a)

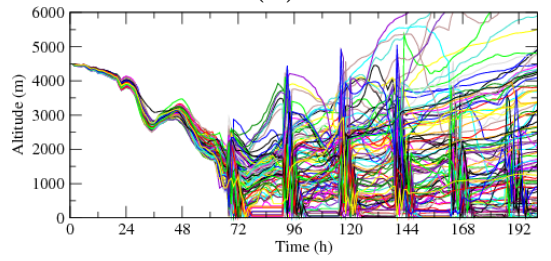

(c)

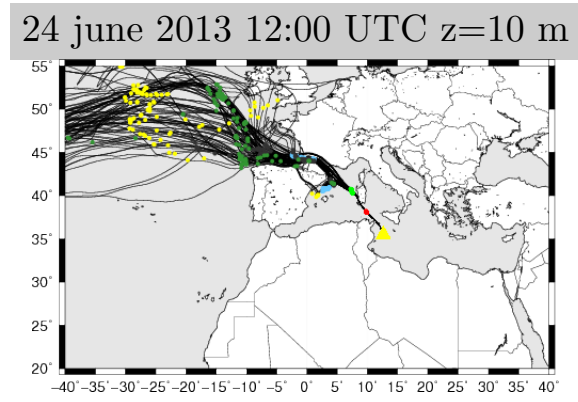

(b)

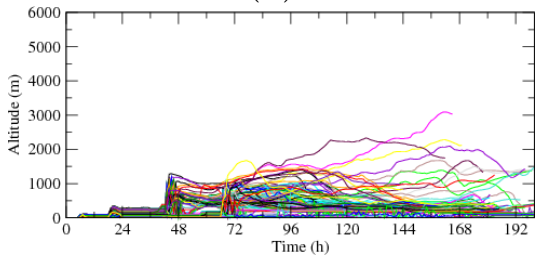

(d)

Figure 12. (a) Back plume starting above Lampedusa for 23 June, 12:00 UTC, at $4500 \mathrm{~m}$ altitude. The yellow triangle represents Lampedusa, the starting location of the back plume. The coloured dots correspond to the number of hours before the starting time: red is 12, green is 24 , blue is 48 , dark green is 72 , yellow is 96. (b) Same as (a) but for 24 June, 12:00 UTC, at $10 \mathrm{~m}$ altitude. (c) Altitude of the back plume starting above Lampedusa for 23 June, 12:00 UTC, at $4500 \mathrm{~m}$ altitude. (d) Altitude of the back plume starting above Lampedusa for 24 June, 12:00 UTC, at $10 \mathrm{~m}$ altitude.

Table 4. Statistical scores for the regression of hourly modelled $J\left(\mathrm{O}^{1} \mathrm{D}\right)$ and $J\left(\mathrm{NO}_{2}\right)$ values against measurements, for hourly values and daily maxima.

\begin{tabular}{lrrrr|rrrr}
\hline & \multicolumn{4}{c}{$J\left(\mathrm{O}^{1} \mathrm{D}\right)$} & \multicolumn{4}{c}{$J\left(\mathrm{NO}_{2}\right)$} \\
& \multicolumn{2}{c}{ Hourly values } & \multicolumn{2}{c}{ Daily maxima } & \multicolumn{2}{c}{ Hourly values } & \multicolumn{2}{c}{ Daily maxima } \\
\hline & REF & NA & REF & NA & REF & NA & REF & NA \\
\hline$N$ & 490 & 490 & 26 & 26 & 578 & 698 & 26 & 26 \\
Slope & 0.98 & 1.02 & 0.31 & 0.05 & 1.09 & 1.07 & 1.13 & -0.005 \\
$R$ & 0.981 & 0.972 & 0.46 & 0.09 & 0.993 & 0.987 & 0.92 & -0.05 \\
$p$ & $<10^{-10}$ & $<10^{-10}$ & 0.02 & 0.65 & $<10^{-10}$ & $<10^{-10}$ & $<10^{-10}$ & 0.81 \\
Bias $(\%)$ & -5.8 & +2.3 & -1.8 & +5.3 & +4.8 & +12.9 & +8.2 & +12.3 \\
\hline
\end{tabular}

clearly shows that taking into account the optical effect of aerosols gives a strong added value in the capacity of a model to reproduce day-to-day variations in $J\left(\mathrm{NO}_{2}\right)$.

It is also interesting to examine the representation of the diurnal cycles of $J\left(\mathrm{O}^{1} \mathrm{D}\right)$ and $J\left(\mathrm{NO}_{2}\right)$ in CHIMERE for both clear days and days with a moderate AOD. For that purpose, based on AOD value and data availability, we selected two non-cloudy days: 18 June as a representative clear-sky day and 23 June as a day representative of a moderate dust outbreak. Measured AOD value is about 0.1 for 18 June and modelled AOD about 0.12 for the same day, while for 23 June measured AOD is about 0.35 and modelled AOD is about 0.45 in average. Figure 14a shows the simulated and observed diurnal cycle of $J\left(\mathrm{NO}_{2}\right)$ for these 2 days. For 18 June (Fig. 14a), it can be seen that the values in the morning and the evening are simulated very realisti- cally by both simulations, while both simulations overestimate $J\left(\mathrm{NO}_{2}\right)$ around local noon. For 23 June, the time evolutions of measured $J\left(\mathrm{NO}_{2}\right)$ have variations from one hour to another. The modelled $J\left(\mathrm{NO}_{2}\right)$ values in the REF simulations do not have such variations, suggesting that the spatial resolution of the CHIMERE model and the smoothing of dust plumes by numerical diffusion lead CHIMERE to miss some fine-scale spatial structures of the plume. Despite this lack of rapid variations, the REF simulation does much better than the NA simulation in representing $J\left(\mathrm{NO}_{2}\right)$ for that day. The simulated values for the REF simulations are either stronger or weaker than the measured values, depending on the hour. The systematic overestimation of $J\left(\mathrm{NO}_{2}\right)$ by the model around local noon is still present for that day, but the model bias is much weaker in the REF simulation than in the NA simulation. 


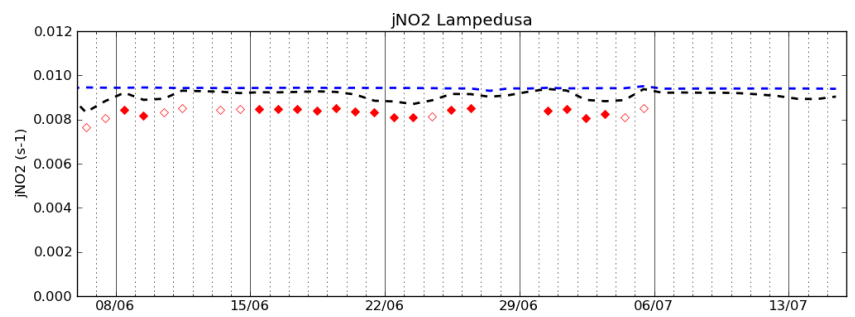

(a)

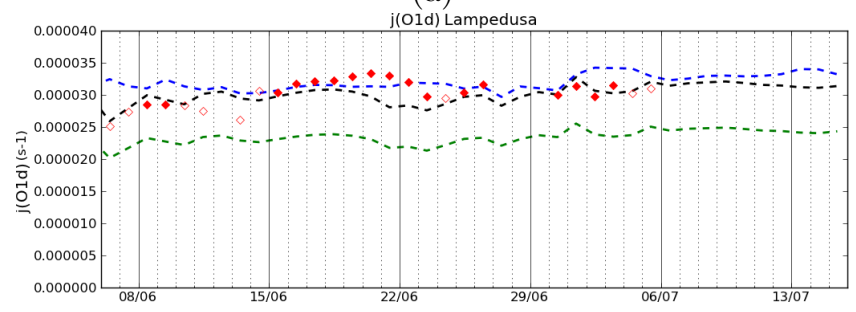

(b)

Figure 13. (a) Daily maximal values of modelled $J\left(\mathrm{NO}_{2}\right)$ in $\mathrm{s}^{-1}$ for the REF simulation (black dashed line) and the NA simulation (blue dashed line), and measured values of the daily maxima (red diamonds). The days when significant effect of clouds was visible on the spectrometer measurements are signalled on the plot by an empty red diamond. (b) Same as (a) for $J\left(\mathrm{O}^{1} \mathrm{D}\right)$. The green dashed line represents the $J\left(\mathrm{O}^{1} \mathrm{D}\right)$ values in the $\mathrm{O} 3+$ simulation.

A scatter plot of modelled vs. observed $J\left(\mathrm{NO}_{2}\right)$ values (Fig. 15a) confirms that the relationship between observed and modelled $J\left(\mathrm{NO}_{2}\right)$ values is excellent for both simulations, even though discrepancies between observed and simulated values are stronger in the NA simulation than in the REF simulation. The correlation coefficient (Table 4) is higher in the REF simulation (0.993) than in the NA simulation (0.987), being excellent in both cases. Since $J\left(\mathrm{NO}_{2}\right)$ is essentially a function of the solar zenith angle, these very high correlation coefficients primarily show that the dependence of $J\left(\mathrm{NO}_{2}\right)$ on the solar zenith angle is represented very well by the CHIMERE model.

\subsubsection{Comparison of modelled $J\left(\mathrm{O}^{1} \mathrm{D}\right)$ to observations}

Figure 13b shows the time series of the daily maxima of $J\left(\mathrm{O}^{1} \mathrm{D}\right)$ for both the REF and the NA simulation as well as in the measurements when available.

Comparison of the daily maxima between the REF and the NA simulation shows that the effect of the aerosols above Lampedusa on the $J\left(\mathrm{O}^{1} \mathrm{D}\right)$ for that period reduces the daily maximum of $J\left(\mathrm{O}^{1} \mathrm{D}\right)$ by 3 to $20 \%$, depending on the AOD (Fig. 13b). The minimal value of the daily maximum $J\left(\mathrm{O}^{1} \mathrm{D}\right)$ is reached on 6 June, both in the REF simulation and in the observations, possibly due to a sharp peak in AOD for that day (Fig. 7a). The peak in modelled dust load and in simulated and observed AOD between 20 and 25 June (Fig. 7a) generates another period of strong impact of aerosols on $J\left(\mathrm{O}^{1} \mathrm{D}\right)$, both in the model and in the observations.
From a statistical point of view (Table 4), the NA simulation, without the direct effect of the aerosols, has no ability to reproduce the day-to-day variations of $J\left(\mathrm{O}^{1} \mathrm{D}\right)$ maxima $(R=0.09, p$ value $=0.65)$. On the contrary, the REF simulation, including the aerosol direct effect, has a correlation coefficient of 0.46 to the observations and a $p$ value of 0.02 that gives good confidence in this result despite the reduced size of the sample (26 points). This shows that taking into account the direct optical effect of the aerosols permits to CHIMERE to better represent the measured day-to-day variations of $J\left(\mathrm{O}^{1} \mathrm{D}\right)$.

The correlation coefficient of daily maxima in $J\left(\mathrm{O}^{1} \mathrm{D}\right)$ between the REF simulation and the observed values is only 0.46 , much lower than the value of 0.92 obtained for $J\left(\mathrm{NO}_{2}\right)$ correlation. This lower value can be explained by the fact that, even when clouds are not present, $J\left(\mathrm{O}^{1} \mathrm{D}\right)$ is influenced by other factors than the AOD, and first of all by the total ozone column. From that point of view, the period for which measurements of $J\left(\mathrm{O}^{1} \mathrm{D}\right)$ are available, from 5 June to 5 July, can be separated into two periods according to the total ozone column (Fig. 3). In the first half of June, until 13 June, the values of ozone column oscillate around 340 DU; in the second half of June and the beginning of July, it oscillates around $310 \mathrm{DU}$. This transition is reflected in Fig. $13 \mathrm{~b}$ by stronger $J\left(\mathrm{O}^{1} \mathrm{D}\right)$ values after 14 June than before 13 June, corresponding to a thinner ozone column. This large variation of the measured $J\left(\mathrm{O}^{1} \mathrm{D}\right)$ values is not captured by the model, which uses prescribed values for stratospheric ozone. The dependence on temperature is also a possible explanation of the different variations between the observed and modelled $J\left(\mathrm{O}^{1} \mathrm{D}\right)$ values, since the modelled temperature values in the boundary layer are not representative of the local temperature at Lampedusa (Fig. 1). On the contrary, $J\left(\mathrm{NO}_{2}\right)$ has only a marginal dependence on the total ozone column, which explains the very high correlation coefficient obtained between the observed and modelled values (0.92). Therefore, the moderate correlation of daily maxima of $J\left(\mathrm{O}^{1} \mathrm{D}\right)(0.46)$ between modelled and observed values must not be blamed on a bad representation of aerosols in the model but rather on the absence of variations of the stratospheric ozone column in the model.

As for $J\left(\mathrm{NO}_{2}\right)$, we examine the diurnal cycles for 18 and 23 June, considered as representative of clear days and days with a strong AOD respectively. Looking at the clear-sky measured and modelled diurnal cycles, (Fig. 14c), as could be expected, we see that the simulated $J\left(\mathrm{O}^{1} \mathrm{D}\right)$ values in the NA simulation are barely different from those in the REF simulation, revealing a very small impact of the AOD on photolytic rates for that day. Comparison of simulated $J\left(\mathrm{O}^{1} \mathrm{D}\right)$ to the observed values (Fig. 14c) shows that both simulation simulate quite realistically the observed $J\left(\mathrm{O}^{1} \mathrm{D}\right)$ for that day, with a slight underestimation of $J\left(\mathrm{O}^{1} \mathrm{D}\right)$ by the model, particularly around local noon. The general shape of the diurnal cycle of $J\left(\mathrm{O}^{1} \mathrm{D}\right)$ is captured very well by the model. For 23 June, on the contrary, the REF and the NA simulations 
June 18 (clear sky)

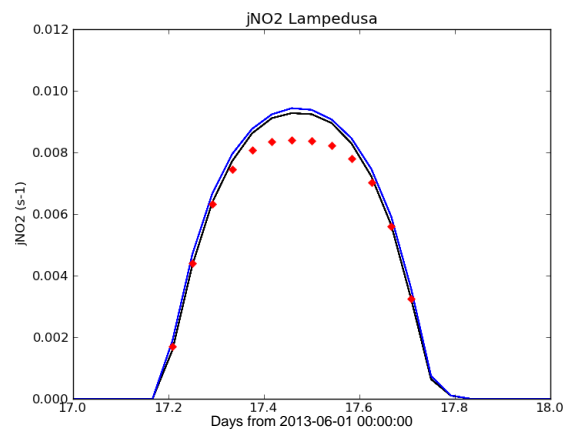

(a)

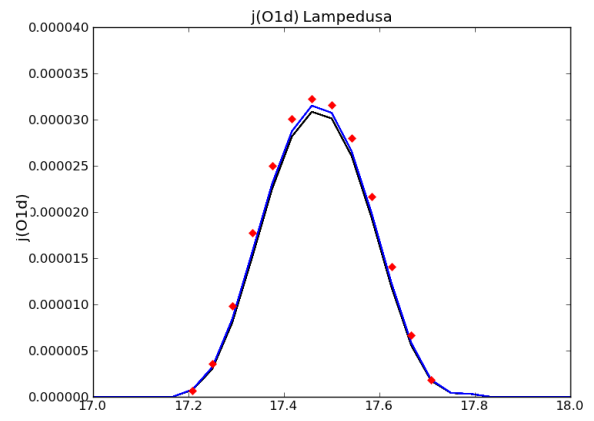

(c)
June 23 (dust outbreak)

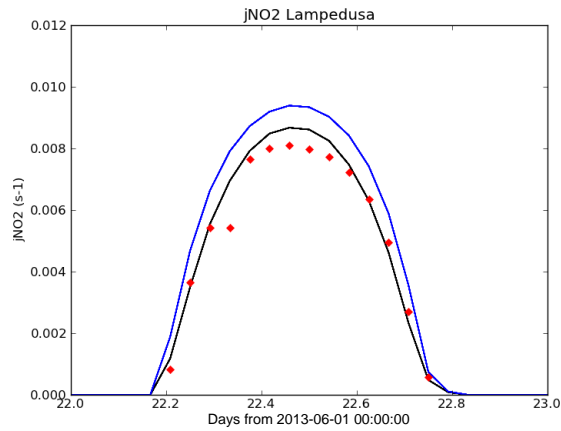

(b)

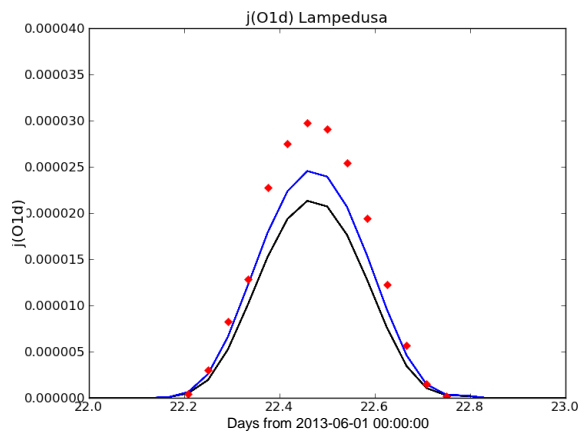

(d)

Figure 14. (a) Hourly modelled values of $J\left(\mathrm{NO}_{2}\right)$ in the REF simulation (black line) and in the NA simulation (blue line), and hourly measured values of $J\left(\mathrm{NO}_{2}\right)$ (red diamonds), for 18 June 2013. (b) Same as (a) but for 23 June; (c) hourly modelled values of $J\left(\mathrm{O}^{1} \mathrm{D}\right)$ in the REF simulation (black line) and in the NA simulation (blue line), and hourly measured values of $J\left(\mathrm{O}^{1} \mathrm{D}\right)$ (red diamonds), for 18 June 2013 ; (d) same as (c) but for 23 June.

are very different due to the strong dust column. Compared to 18 June, the reduction in $J\left(\mathrm{O}^{1} \mathrm{D}\right)$ is strong for both the REF simulation (11\% at local noon) and the measured values $(7 \%)$. It is worth noting that the weaker reduction of the measured $J\left(\mathrm{O}^{1} \mathrm{D}\right)$ compared to the simulated $J\left(\mathrm{O}^{1} \mathrm{D}\right)$ between June 18 and June 23 can also be attributed to a compensation between the optical effect of aerosols, tending to reduce observe $J\left(\mathrm{O}^{1} \mathrm{D}\right)$, and the thinning ozone column between these two dates (Fig. 3), tending to compensate the effect of dust. This compensation effect between the effects of changes in AOD and in total ozone column on surface UV irradiance, and thus also on $J\left(\mathrm{O}^{1} \mathrm{D}\right)$, has been discussed by di Sarra et al. (2002), who have shown that during spring and summer at Lampedusa, the synoptic conditions leading to dust transport also induce thinner ozone columns.

Figure 15a confirms that the representation of the diurnal cycle of $J\left(\mathrm{O}^{1} \mathrm{D}\right)$ at Lampedusa by the Fast-JX module within CHIMERE is very satisfactory. The linear correlation coefficient between the observed and modelled value for the REF simulation is of 0.981 , slightly stronger than the value of 0.972 obtained for the NA simulation (Table 4). The high values of these correlation coefficients for both simulations confirm that the general shape of the diurnal cycle of $J\left(\mathrm{O}^{1} \mathrm{D}\right)$ is captured very well by both simulations, confirming that the dependence of $J\left(\mathrm{O}^{1} \mathrm{D}\right)$ on the solar zenith angle is represented correctly by the CHIMERE model. The average of the 610 valid data points, representative of average daytime $J\left(\mathrm{O}^{1} \mathrm{D}\right)$ during the simulation, is lower by $5.8 \%$ when compared to the observations, while the NA simulation has a positive bias of $2.3 \%$.

\subsubsection{Dependence of $J\left(\mathrm{O}^{1} \mathrm{D}\right)$ and $J\left(\mathrm{NO}_{2}\right)$ on the AOD at fixed zenith angle}

Finally, in order to evaluate directly the impact of the aerosols on $J\left(\mathrm{O}^{1} \mathrm{D}\right)$ and $J\left(\mathrm{NO}_{2}\right)$, as in Gerasopoulos et al. (2012) and Casasanta et al. (2011), we produced scatter plots representing the modelled photolysis rates as a function of the modelled AOD at $400 \mathrm{~nm}$ for clear sky conditions and for a fixed zenith angle (Fig. 16). These scatter plots have been produced by selecting, for all the model points located at about the same latitude as Lampedusa $\left(35.5^{\circ} \mathrm{N} \pm 3^{\circ}\right)$, the times when no clouds are present in the model and for which the SZA corresponds to the target SZA $\left(30\right.$ and $\left.60^{\circ}\right)$ within a tolerance margin of $\pm 1^{\circ}$. As discussed above, the modelled 


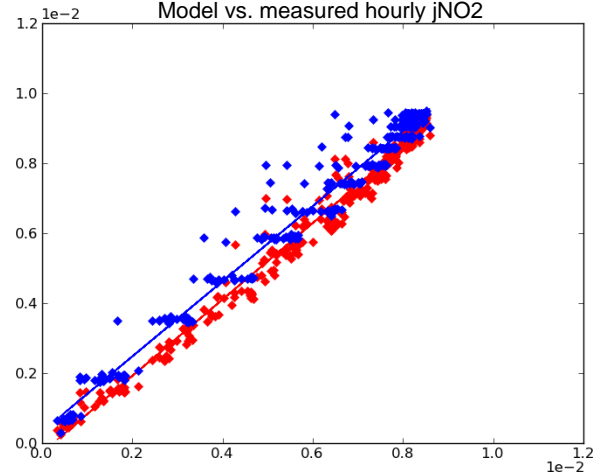

(a)

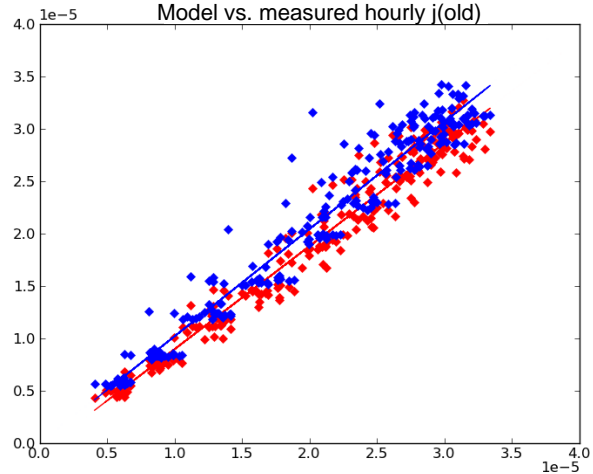

(b)

Figure 15. (a) Scatter plot of hourly modelled $J\left(\mathrm{NO}_{2}\right)$ vs. measured $J\left(\mathrm{NO}_{2}\right)$ at Lampedusa for 698 points with valid daytime measurements of $J\left(\mathrm{NO}_{2}\right)$. Red diamonds represent the $J\left(\mathrm{NO}_{2}\right)$ values in the REF simulation, blue diamonds the $J\left(\mathrm{NO}_{2}\right)$ values in the NA simulation, with the respective regression lines; (b) same as (a) for $J\left(\mathrm{O}^{1} \mathrm{D}\right)$, with 610 valid data points.

photolysis rates have been multiplied by $\frac{1}{1+A}$, where $A$ is the albedo, fixed at 0.1 in the model, in order to permit the comparison of the model outputs with measurements that take into account only the downward actinic flux. The size of the data set for modelled values is very large (12637 points for panels a and c; 12916 points for panels $b$ and d) and describe an AOD range from 0 to values that largely exceed unity. The regression lines provided by Gerasopoulos et al. (2012) for $J\left(\mathrm{NO}_{2}\right)$ and by Casasanta et al. (2011) have also been superimposed to the scatter plots displayed for comparison. It is worth noting at this point that, during our simulation period, no significant AOD peaks have been simulated due to non-dust aerosols, so that the scatter plot obtained in the REF simulation (Fig. 16b) shall be compared to the red regression line given by Gerasopoulos et al. (2012) for cases when dust predominates rather than to the blue regression line given for cases when non-dust aerosols predominate.

Regarding $J\left(\mathrm{NO}_{2}\right)$, Fig. 16b reproduces the linear relationships given in Gerasopoulos et al. (2012) (their Fig. 6) for $J\left(\mathrm{NO}_{2}\right)$ vs. AOD at $60^{\circ}$ zenith angle. The red line concerns the relationship they establish when the AOD is predominantly due to dust, and the blue line is for AOD predominantly due to other aerosols. From the location of our modelled points relative to these linear relationships established from measurement data, it can be said that the quasilinear dependence between $J\left(\mathrm{NO}_{2}\right)$ and the AOD for a fixed zenith angle is reproduced very well by the Fast-JX module in CHIMERE. It can also be inferred from this figure that the relationship between $J\left(\mathrm{NO}_{2}\right)$ and the AOD proposed by Gerasopoulos et al. (2012) for the cases when dust aerosols predominates seems to be valid much beyond the AOD range observed in their data set, which only covered AOD values up to 0.65 , compared to 1.9 in Fig. $16 \mathrm{~b}$. For a SZA value of $30^{\circ}$ (Fig. 16a), the dependence of $J\left(\mathrm{NO}_{2}\right)$ on the AOD is also consistent with the results of Gerasopoulos et al. (2012): the Fig. 10 of these authors indicates an effect between 10 and $15 \%$ on $J\left(\mathrm{NO}_{2}\right)$ for an AOD value of 0.7 , very similar to what we observe in Fig. 16a. At that point, it is worth going back to Table 4. Analysis of the correlation (0.92) and slope (1.13) of the linear regression between observed and simulated daily maximal values, representative of SZA values ranging between 12 and $13^{\circ}$, shows that, for the very small SZA values corresponding to solar noon conditions at Lampedusa, the effect of the aerosol optical depth on $J\left(\mathrm{NO}_{2}\right)$ at very small SZA values is represented realistically as well.

Regarding $J\left(\mathrm{O}^{1} \mathrm{D}\right)$, panels $\mathrm{c}$ and $\mathrm{d}$ of Fig. 16 present the scatter plots of $J\left(\mathrm{O}^{1} \mathrm{D}\right)$ in this study against AOD for cloudfree condition at a SZA of 30 and $60^{\circ}$ respectively. The correlation lines provided by Casasanta et al. (2011) (their Table 2) are also reported on these panels, along with the maximal and minimal hypothesis obtained by applying to the slope and intercept values an uncertainty margin of $\pm 2.5 \sigma$, where the uncertainty value $\sigma$ is provided by these authors. We chose to apply the relationships obtained by Casasanta et al. (2011) for a total ozone column of 280-290 DU, which is the closest values to the modelled ozone columns in the present study. At $30^{\circ}$, the simulated relationship between AOD and $J\left(\mathrm{O}^{1} \mathrm{D}\right)$ in this study is within the uncertainty range of the linear relationships given by Casasanta et al. (2011), with a large spread in modelled data, maybe due to the very different surface temperatures that can be observed across the domain even at a constant latitude. The reduction of $J\left(\mathrm{O}^{1} \mathrm{D}\right)$ by a unit AOD in the simulated values is of about $25 \%$, smaller than the value of $38 \%$ that can be obtained from the results of Casasanta et al. (2011) (their Table 2). This seems to indicate that the effect of the AOD on $J\left(\mathrm{O}^{1} \mathrm{D}\right)$ might be underestimated by the Fast-JX algorithm within the CHIMERE model, which is even more the case for $60^{\circ}$ SZA (Fig. 16d), for which the modelled scatter plot is clearly out of the uncertainty range obtained by applying a $\pm 2.5 \sigma$ uncertainty margin to the slope given by these authors. Therefore, it seems 
that the effect of the AOD on $J\left(\mathrm{O}^{1} \mathrm{D}\right)$ in CHIMERE might be underestimated, particularly for the high SZA values.

\subsection{Impact of the aerosols on the concentration of trace gases}

Time series of the simulated ozone concentration is shown in Fig. 17a for the Lampedusa station and compared to measurements. Figure 17a shows that the agreement between model and measurements at Lampedusa for the simulation period is rather satisfying. The ozone concentrations evolve between 30 and $70 \mathrm{ppb}$ during this period, with a diurnal cycle of about $10 \mathrm{ppb}$ which is captured by the model. The model is also able to capture the low ozone period between 20 June and 5 July, and the higher ozone concentrations before and after that period. Fig. 17b shows the net effect of the AOD on ozone concentration at Lampedusa showing that the effect of the AOD on ozone concentration is almost always negative at that location, reaching almost $-2 \mathrm{ppb}$ during the dust outbreak of 20-25 June above Lampedusa, for a simulated AOD about 0.4 .

Figure 18 shows the spatial distribution of the aerosol effects on photochemistry averaged over the whole simulated period. The effect of the AOD on both $J\left(\mathrm{O}^{1} \mathrm{D}\right)$ and $J\left(\mathrm{NO}_{2}\right)$ ranges between a few percents for areas in the northern parts of the domain that present a small average AOD, and about $20 \%$ in the areas that are close to the sources of dust in Africa or downwind of them over the tropical Atlantic Ocean. Over the whole domain, as could be expected, the average effect of aerosols is to reduce both $J\left(\mathrm{O}^{1} \mathrm{D}\right)$ and $J\left(\mathrm{NO}_{2}\right)$, affecting both rates in a very similar proportion. Regarding the net average effect of the AOD on ozone concentration, the picture is very contrasted (Fig. 18c). Over the Mediterranean Sea, the north-east Atlantic and continental Europe, as well as parts of equatorial Africa, the effect of the reduction in photolytic rates leads to a net average reduction in ozone concentrations, as could be seen for Lampedusa in Fig. 17. This reduction locally reaches $1 \mathrm{ppb}$ over the Mediterranean basin, as well as in areas of equatorial Africa. On the contrary, over the Sahara as well as over the tropical Atlantic below the dust plume, ozone concentration seems to be increased by this reduction in the photochemical reaction rates.

In order to examine the vertical distribution of these differences in ozone concentration, we produced vertical profiles of the time-mean of $\left[\mathrm{O}_{3}\right]_{\mathrm{REF}}-\left[\mathrm{O}_{3}\right]_{\mathrm{NA}}$ for two large spatial sectors: one for $35-45^{\circ} \mathrm{N} \times 5^{\circ} \mathrm{W}-35^{\circ} \mathrm{E}$, including the Mediterranean Sea and the surrounding continental areas (Fig. 19a), and one for $5-30^{\circ} \mathrm{N} \times 10^{\circ} \mathrm{W}-30^{\circ} \mathrm{E}$, including the Sahara (Fig. 19b). Consistently with Fig. 18, the optical effect of the aerosols on ozone concentrations is of opposite signs in these two sectors: negative in the Mediterranean basin, positive in the Saharan area. However, the vertical profile of the anomaly is very different in these two areas. In the Mediterranean basin, the optical effect of the aerosols on the ozone concentration is maximal in the vicin- ity of the ground and very small when the altitude is above $2000 \mathrm{~m}$ a.g.l., changing sign to become marginally positive above $3000 \mathrm{~m}$ a.g.l. (Fig. 19a). This vertical profiles may suggest that the dominant effect in this area is the screening of incoming solar radiation by aerosol layers located in the lowest $2000 \mathrm{~m}$ of the troposphere. Contrarily, in the Saharan area, the effect of aerosols on ozone is a positive one, with maximal around $3000 \mathrm{~m}$ a.g.l. These very different vertical profiles for the Mediterranean basin and the Saharan area call for additional studies addressing the vertical structure of the aerosol-related anomalies of photolysis rates and their final effect on ozone concentrations, depending on the chemical regime.

Comparison of Fig. 18c with the $\mathrm{NO}_{x}$ emissions as shown in Fig. 2 shows that the effect of the reduction of the photolysis rates by aerosol screening depends on the presence of important $\mathrm{NO}_{x}$ emissions. In areas close to significant sources of $\mathrm{NO}_{x}$ such as continental Europe, coastal North Africa, Turkey and the Middle East, Nigeria and the shipping routes in the Mediterranean and the Red Sea, the effect of aerosol screening is to reduce ozone concentrations by reducing its photochemical production through the photodissociation of $\mathrm{NO}_{2}$, due to the decrease of $J\left(\mathrm{NO}_{2}\right)$. Contrarily, over remote areas such as the Sahara and the tropical Atlantic, the effect of aerosol screening is to increase ozone concentrations, most likely by reducing photochemical dissociation of ozone. This confirms the findings of Bian et al. (2003) in a global-scale CTM: these authors also observed in their model that the sign of the effect of AOD on ozone concentrations changes according to the photochemical regime, due to the competition effect between reduced ozone formation due to the reduction of $J\left(\mathrm{NO}_{2}\right)$ and reduced ozone destruction due to the reduction of $J\left(\mathrm{O}^{1} \mathrm{D}\right)$, yielding, according to the photochemical regime, a positive, negative or neutral effect of AOD on ozone concentration.

\subsection{Sensitivity to a bias in total ozone column}

The total ozone column in the model is biased towards low values when compared to observations (Fig. 3). In order to measure the impact of this underestimation on the ability of the CHIMERE model to accurately simulate the value of $J\left(\mathrm{O}^{1} \mathrm{D}\right)$ in the troposphere, it is interesting to examine at this point the outputs of the $\mathrm{O} 3+$ simulation performed enhancing the ozone concentrations used for radiative calculations throughout the atmosphere, thereby compensating the bias on ozone column visible in Fig. 3. The effect of this increase of $18 \%$ of the total ozone column is the reduction of the modelled $J\left(\mathrm{O}^{1} \mathrm{D}\right)$ by about $20 \%$ in Lampedusa (Fig. 13) as well as in the rest of the domain (not shown), with a stronger reduction in the northern part of the domain and a weaker reduction in the south. As the bias in $J\left(\mathrm{O}^{1} \mathrm{D}\right)$ was weak in the REF run (Fig. 13), the $J\left(\mathrm{O}^{1} \mathrm{D}\right)$ photolytic rates in the $\mathrm{O} 3+$ simulation have a strong negative bias of about $20 \%$ compared to the measured values. The temporal variations of 


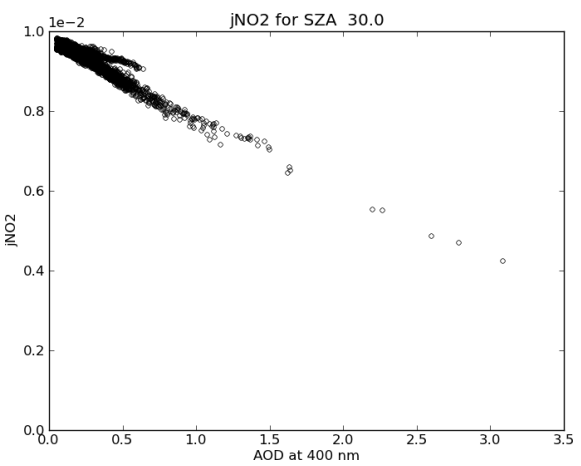

(a)

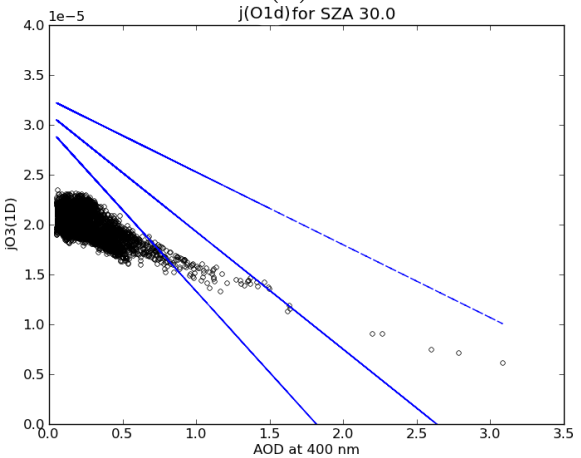

(c)

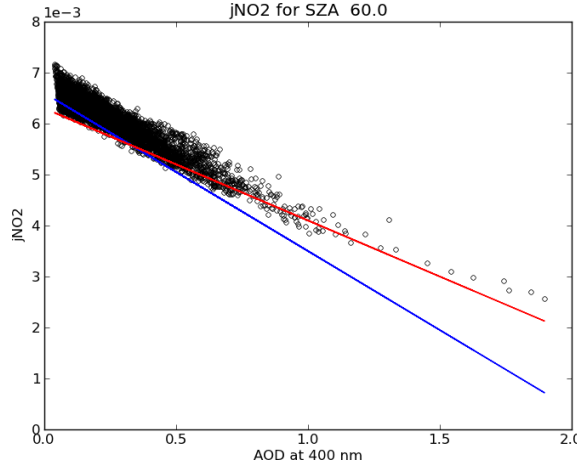

(b)

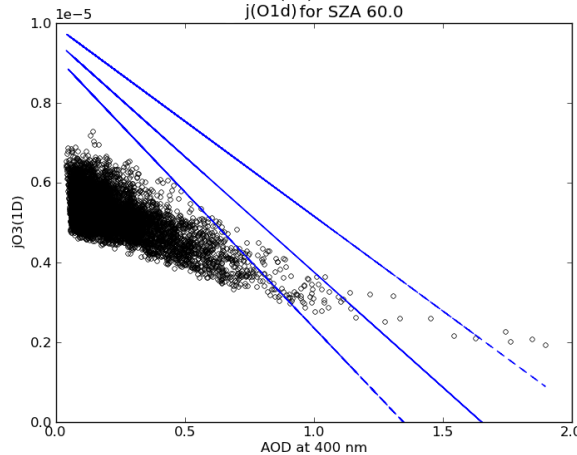

(d)

Figure 16. Scatter plots of $J\left(\mathrm{NO}_{2}\right)(\mathbf{a}, \mathbf{b})$ and $J\left(\mathrm{O}^{1} \mathrm{D}\right)(\mathbf{c}, \mathbf{d})$ at the lowest model level vs. the AOD, for clear-sky conditions ant latitudes comprised between 32.5 and $38.5^{\circ} \mathrm{N}$. For the purpose of comparison, the regression relationships found by Gerasopoulos et al. (2012) with field data are reported in blue (non-dust aerosols) and red (dust aerosols) in panel (b). In panels (c) and (d) the regression lines by Casasanta et al. (2011) are indicated along with their uncertainty margin.

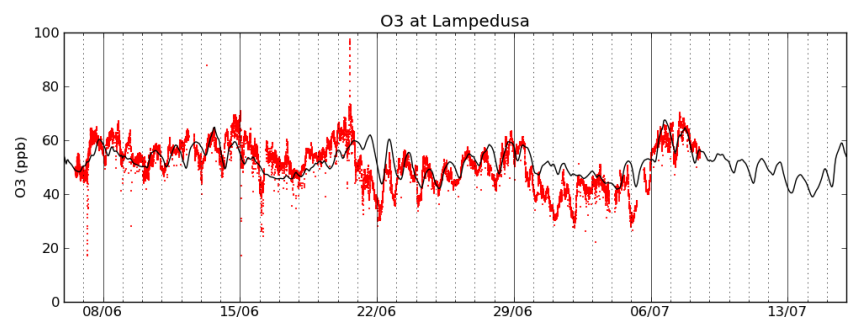

(a)

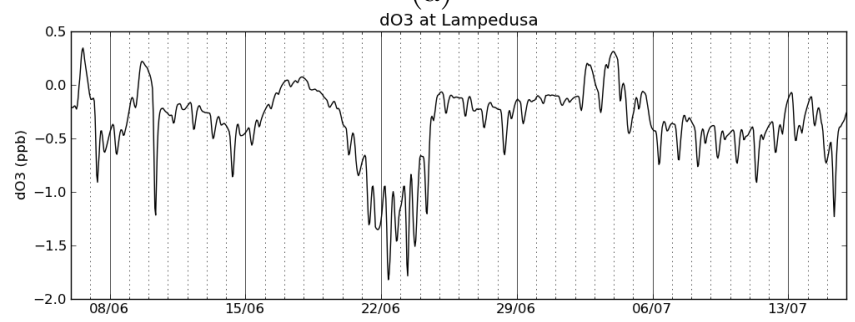

(b)

Figure 17. (a) Time series for ozone concentration $(\mathrm{ppb})$ in the reference simulation in Lampedusa (black line) along with measured values (red dots); (b) effect of the optical screening by the aerosols on the ozone concentration, computed as $\mathrm{dO}_{3}=\left[\mathrm{O}_{3}\right]_{\mathrm{ref}}-\left[\mathrm{O}_{3}\right]_{\mathrm{NA}}$.
$J\left(\mathrm{O}^{1} \mathrm{D}\right)$ are not changed very much by this debiasing of the ozone column content (Fig. 13).

As expected (Fuglestvedt et al., 1994), $J\left(\mathrm{NO}_{2}\right)$ values show a very small sensitivity to this debiasing of the ozone column. The increase of $18 \%$ in the model ozone column results in a reduction by about $0.3 \%$ of the average $J\left(\mathrm{NO}_{2}\right)$ over the entire domain.

The effect of the modification of the ozone column on ozone concentrations is significant (Fig. 20), with an increase of up to $4 \mathrm{ppb}$ of the ozone concentrations over remote areas such as the Saharan area and the eastern Mediterranean and a weaker increase of ozone concentrations over continental Europe. This increase of ozone concentrations can be attributed to the reduction of ozone photolysis due to the increased ozone column and the reduced value of $J\left(\mathrm{O}^{1} \mathrm{D}\right)$. Interestingly, this reduction of $J\left(\mathrm{O}^{1} \mathrm{D}\right)$ has the opposite effect over the North Sea, resulting in slightly increased ozone concentrations (about $1 \mathrm{ppb}$ ). Generally speaking, it is visible in Fig. 20 that in regions having large anthropogenic emissions such as northern Europe, the Po valley and regions with intense shipping in the Mediterranean, Atlantic, North Sea and Baltic Sea, the effect of the reduced $J\left(\mathrm{O}^{1} \mathrm{D}\right)$ on ozone con- 


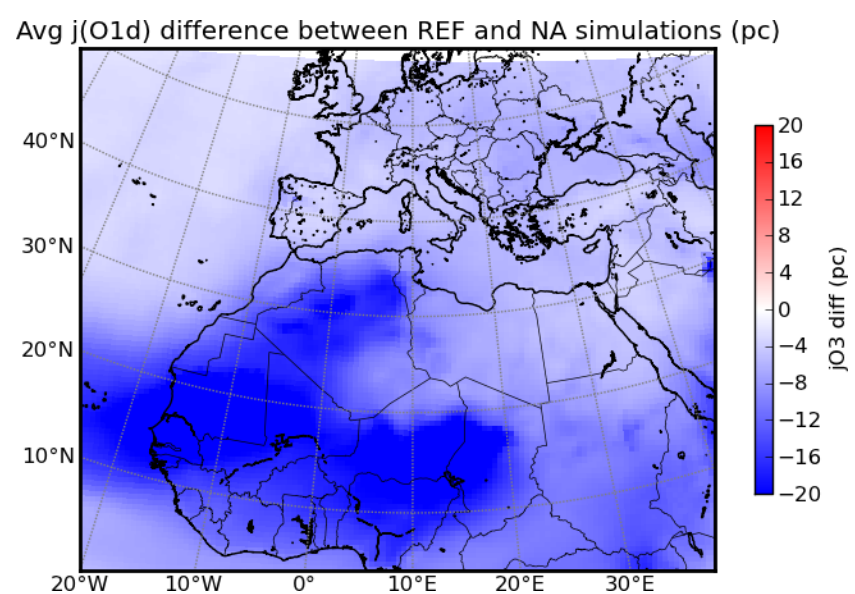

(a)

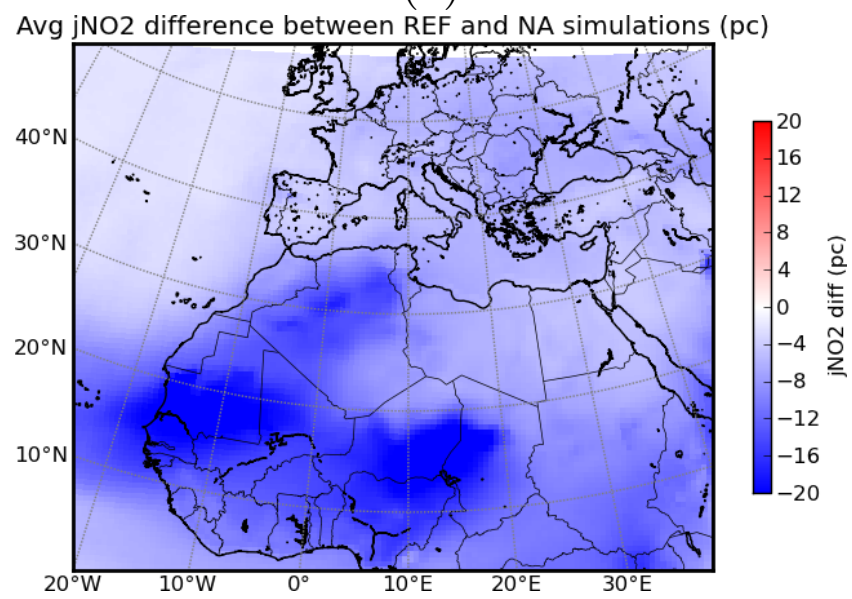

(b)

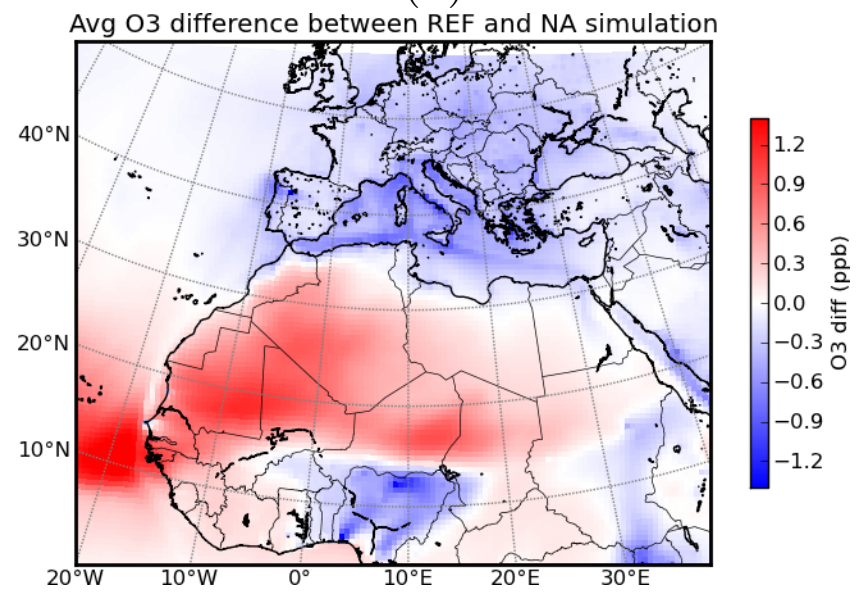

(c)

Figure 18. (a) Average difference of $J\left(\mathrm{O}^{1} \mathrm{D}\right)$ between REF and NA (\%) for all the simulation period (6 June-15 July); (b) average difference of $J\left(\mathrm{NO}_{2}\right)$ between REF and NA $(\%)$ for the entire simulation period; (c) average difference of ozone concentration between REF and NA for all the simulation period (ppb).

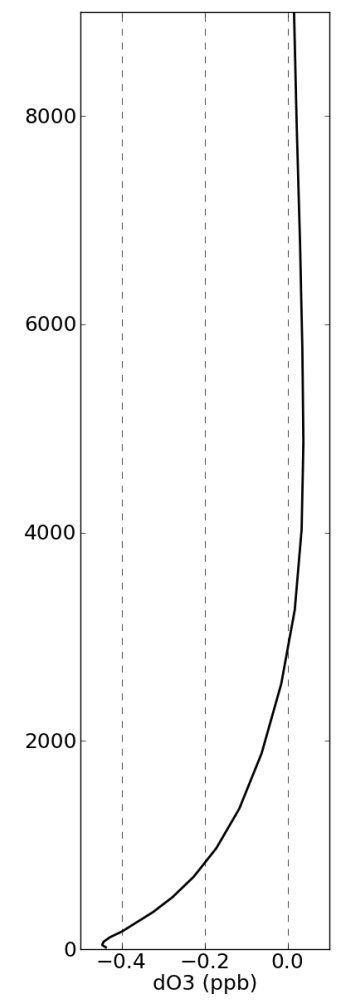

(a)

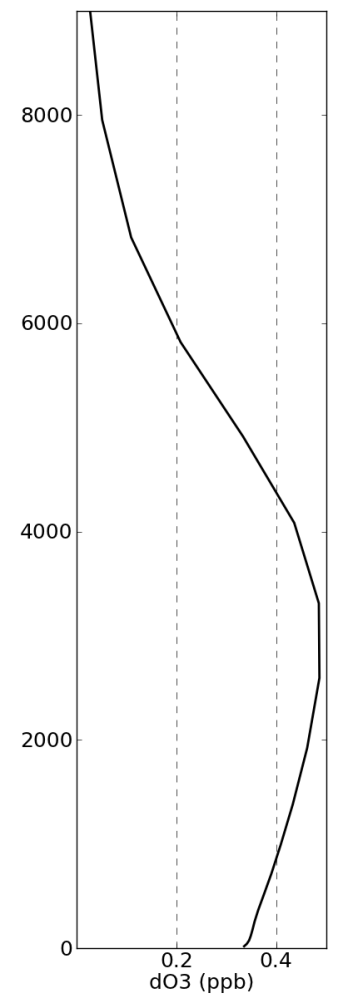

(b)
Figure 19. (a) $\left[\mathrm{O}_{3}\right]_{\mathrm{REF}}-\left[\mathrm{O}_{3}\right]_{\mathrm{NA}}$ as a function of the height in metres above the ground level (m a.g.l), averaged for the Mediterranean basin $\left(35-45^{\circ} \mathrm{N} \times 5^{\circ} \mathrm{W}-35^{\circ} \mathrm{E}\right)$ for all the simulation period (6 June-15 July); (b) same as (a) but for the Saharan area (5$\left.30^{\circ} \mathrm{N} \times 10^{\circ} \mathrm{W}-30^{\circ} \mathrm{E}\right)$.

centrations is weak, while it is much stronger in areas far away from the main emissions zones.

The fact that taking into account a debiased ozone column creates a negative bias on $J\left(\mathrm{O}^{1} \mathrm{D}\right)$ suggest that, from a modelling point of view, using Fast-JX version 7.0b as it is provided, even with the fact that the ozone climatology delivered along with the model seems to be biased, gives better results in terms of photolytic rates than when the total ozone column is debiased. This counterintuitive result indicates that, from a practical point of view, it is better to use Fast-JX 7.0b with the stratospheric ozone column as it is provided, because the $J\left(\mathrm{O}^{1} \mathrm{D}\right)$ values calculated with a more realistic ozone column are negatively biased. This highlights the conception of Fast-JX as a tool designed to perform fast and accurate calculations of the photolytic rates within a CTM, rather than a tool made to solve exactly every aspect of the radiative transfers in the atmosphere. 


\section{Conclusions}

Three simulations of the atmospheric composition have been performed for the period covering 6 June-15 July 2013, with a spin-up period from 1 June, for a large domain including the Mediterranean Sea as well as the surrounding continents and the north-eastern part of the Atlantic Ocean. The REF simulation is the same as described in Menut et al. (2015a), while the second simulation is a sensitivity simulation performed without taking into account the optical effect of aerosols on photochemistry (NA simulation). Comparison with MODIS satellite data as well as with AERONET and MFRSR observations shows that the reference simulation reproduces realistic levels of AOD over most of the simulation domain, including the main study area in Lampedusa: in the case of Lampedusa, the correlation coefficient between simulated and observed AOD at $400 \mathrm{~nm}$ is strong (0.8), with an average positive bias of 0.04 in the simulated AOD (19.08\% of the average observed value). These correlation and bias of the simulated vs. observed values vary greatly depending on the measurement stations. For stations in North Africa or around the Mediterranean, the bias is generally moderate ( -35 to $+17,9 \%$ in the ten considered stations) and the correlation coefficients vary from -0.14 to 0.79 . For the two stations that were considered in northern Europe (Palaiseau, France, and Mainz, Germany), the negative bias in the simulated values is strong ( -61.7 and $-45.3 \%$ respectively), with very weak correlation coefficient. It is also of interest to note that the peak AOD values at the Lampedusa and Palma de Mallorca stations tend to be overestimated by up to $50 \%$ by the CHIMERE model during the simulation period.

Regarding the speciation of the aerosols close to the ground at Lampedusa, these simulations show a good capability to represent the non-dust $\mathrm{PM}_{10}$ concentrations at ground level and their variations, mainly due to sea-salt aerosols. Contrarily, the dust concentrations close to the ground level are too strong in the model compared to the observations, possibly indicating an excess of vertical diffusion and/or sedimentation in the model. A third simulation (O3+) has been performed in order to remove the bias in the total ozone column in the model compared to observations above Lampedusa.

Regarding the photolytic rates, it is shown that both the REF and NA simulations simulate the photolytic rates $J\left(\mathrm{O}^{1} \mathrm{D}\right)$ and $J\left(\mathrm{NO}_{2}\right)$ in a satisfactory way for Lampedusa, when compared to in situ measurements. The REF simulation is biased by $5.8 \%$ towards an underestimation of the observed $J\left(\mathrm{O}^{1} \mathrm{D}\right)$ value, and the NA simulation is biased by about $2.3 \%$ towards an overestimation. However, two large uncertainty factors affect the modelled $J\left(\mathrm{O}^{1} \mathrm{D}\right)$ values: the climatology of stratospheric ozone that has been used for this study did not fit the observed total ozone column, and the temperature in the model was negatively biased as well. Regarding the representation of $J\left(\mathrm{NO}_{2}\right)$, the NA simulation exhibits an overestimation of $12.3 \%$ in $J\left(\mathrm{NO}_{2}\right)$ compared to

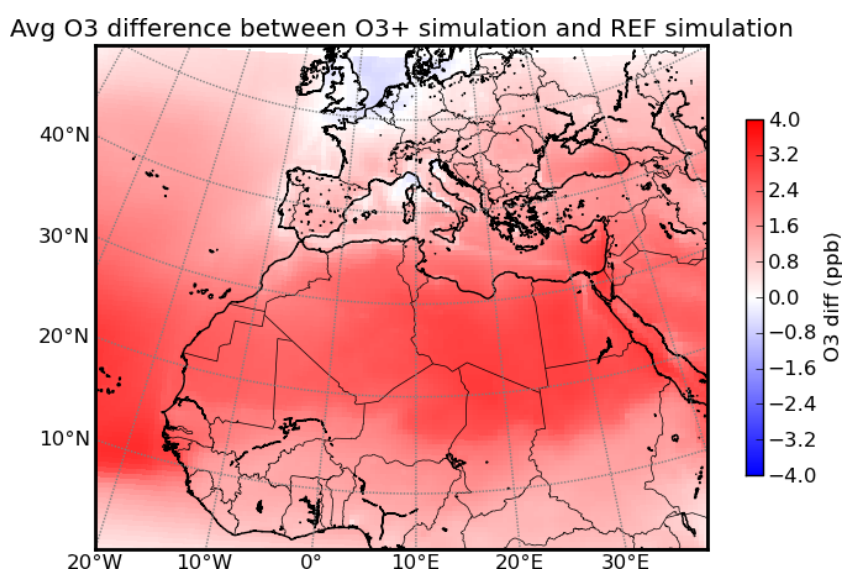

Figure 20. Difference (ppb) in the concentration of ozone in the lowest model layer between the $\mathrm{O} 3+$ simulation and the REF simulation.

observations, which is largely corrected by the inclusion of the aerosols, as reflected by the much smaller bias in the REF simulation $(4.8 \%)$. If we turn to the variations of $J\left(\mathrm{NO}_{2}\right)$ and $J\left(\mathrm{O}^{1} \mathrm{D}\right)$ with time, the correlation coefficient between hourly simulated and measured values is excellent for both simulations, always in excess of 0.97 , reflecting the fact that the diurnal cycle of $J\left(\mathrm{O}^{1} \mathrm{D}\right)$ and $J\left(\mathrm{NO}_{2}\right)$ is represented very realistically by the Fast-JX module within the CHIMERE model. If we remove the impact of the diurnal cycle by comparing the daily maxima of $J\left(\mathrm{O}^{1} \mathrm{D}\right)$ and $J\left(\mathrm{NO}_{2}\right)$ in both simulations to measurements, it becomes clear that the day-today variability of $J\left(\mathrm{O}^{1} \mathrm{D}\right)$ is represented much better in the REF simulation than in the NA simulation. While the simulation without effect of the aerosols is not able to reproduce any of the observed day-to-day variations in $J\left(\mathrm{O}^{1} \mathrm{D}\right)$, the daily maxima of $J\left(\mathrm{O}^{1} \mathrm{D}\right)$ REF simulation are significantly correlated to the observed values. Therefore, despite the strong dependence of $J\left(\mathrm{O}^{1} \mathrm{D}\right)$ on the total ozone column, it is safe to state that the inclusion of the optical effect of aerosols improves the representation of the evolution of $J\left(\mathrm{O}^{1} \mathrm{D}\right)$ in the CHIMERE model. Regarding $J\left(\mathrm{NO}_{2}\right)$, the added value of including the aerosol effects is more spectacular since $J\left(\mathrm{NO}_{2}\right)$ has no strong dependence on the total ozone column (Fuglestvedt et al., 1994). The REF simulation captures almost exactly the day-to-day variations of $J\left(\mathrm{NO}_{2}\right)$ $(R=0.92)$, while the NA simulation does not capture any of these variations, showing that, in the near absence of clouds, representing correctly the effect of the aerosols is a necessary and sufficient condition to represent the day-to-day variations of $J\left(\mathrm{NO}_{2}\right)$.

The relationship between $J\left(\mathrm{O}^{1} \mathrm{D}\right)$ and the AOD at a constant zenith angle, as well as for $J\left(\mathrm{NO}_{2}\right)$ in CHIMERE has been compared to the results of Gerasopoulos et al. (2012) for $J\left(\mathrm{NO}_{2}\right)$ and Casasanta et al. (2011) for $J\left(\mathrm{O}^{1} \mathrm{D}\right)$. This comparison shows that the dependence of $J\left(\mathrm{NO}_{2}\right)$ on the AOD as represented by CHIMERE is very similar to the ob- 
servational results of Gerasopoulos et al. (2012). Our model results indicate a reduction of $J\left(\mathrm{NO}_{2}\right)$ by a unit AOD of about $20 \%$ for a SZA value of $30^{\circ}$ and $35 \%$ for a SZA value of $60^{\circ}$. Regarding $J\left(\mathrm{O}^{1} \mathrm{D}\right)$, the comparison of our model results with the results of Casasanta et al. (2011), obtained from in situ measurements, seems to indicate that the effect of the aerosols on $J\left(\mathrm{O}^{1} \mathrm{D}\right)$ is underestimated in CHIMERE, particularly for high SZA values $\left(60^{\circ}\right)$. However, from a modelling point of view, this caveat is not critical since photochemistry is not very active when the SZA is so high.

Finally, regarding the optical impact of the aerosols on the ozone concentration through the modulation of the photolytic rates, comparison between the REF simulation and the NA simulation shows that, above Lampedusa, the optical effect of the aerosols reduced the ozone concentration by up to almost 2 ppb during the dust transport episode that occurred between June 20 and 25 above Lampedusa. This result is consistent with the results of Bian et al. (2003), and similar to these authors we interpret this reduction as an effect of lower photochemical ozone production in Lampedusa and the surrounding marine and continental areas due to reduced photolysis rates. Over other parts of the simulation domain, such as the Sahara, the impact of optical screening by mineral dust is, on the contrary, to increase the surface ozone concentration. This 2-fold effect of the optical screening of the incoming shortwave radiation by the aerosols might be explained by the balance between the reduction of $J\left(\mathrm{NO}_{2}\right)$, which tends to reduce ozone production particularly in zones under anthropogenic influence, and the reduction of $J\left(\mathrm{O}^{1} \mathrm{D}\right)$, which tends to reduce ozone destruction.

From a modelling point of view, the main conclusion of this study is that including an online representation of the photolysis rates taking into account the real-time simulated aerosol concentrations with a realistic model for radiative transfers such as Fast-JX permits a much better representation of photolytic rates compared to measurements. This is particularly true for $J\left(\mathrm{NO}_{2}\right)$ : the representation of $J\left(\mathrm{O}^{1} \mathrm{D}\right)$ is much more complex, particularly due to the effect of the variations in the total ozone column, which are superimposed to the variations due to the AOD. The impact on ozone concentrations in the present study is moderate (a few ppb), which might be due to the relatively coarse model resolution. The impact of modulation of photolytic rates by the AOD may very well be more important in urban conditions where important aerosol loads from natural and anthropogenic sources occur at the same time and place as massive emissions of nitrogen oxides.

Acknowledgements. We thank the ChArMEx program (sponsored by CNRS-INSU, ADEME, Météo-France and CEA) as well as the ADRIMED program (sponsored by ANR) for permitting the collection of the relevant field data by the principal investigators of the three AERONET stations that have been used in this study: Daniela Meloni for Lampedusa, Diouri Mohammed and Djamaleddine Chabane for Oujda and Juan Ramon Moreta Gonzalez for Palma de Mallorca. Measurements at Lampedusa during ChArMEx were partly supported by the Italian Ministry for University and Research through the NextData and Ritmare projects. The contributions by Lorenzo De Silvestri are gratefully acknowledged. The authors also wish to thank the editor for his careful editorial and scientific review of the initial manuscript as well as the three anonymous reviewers who helped to significantly improve this study.

Edited by: F. Dulac

\section{References}

Alfaro, S. C. and Gomes, L.: Modeling mineral aerosol production by wind erosion: Emission intensities and aerosol size distributions in source areas, J. Geophys. Res., 106, 18075-18084, doi:10.1029/2000JD900339, 2001.

Ancellet, G., Pelon, J., Totems, J., Chazette, P., Bazureau, A., Sicard, M., Di Iorio, T., Dulac, F., and Mallet, M.: Long range transport and mixing of aerosol sources during the 2013 North American biomass burning episode: analysis of multiple lidar observations in the Western Mediterranean basin, Atmos. Chem. Phys. Discuss., 15, 32323-32365, doi:10.5194/acpd-15-323232015, 2015.

Bessagnet, B., Hodzic, A., Vautard, R., Beekmann, M., Cheinet, S., Honoré, C., Liousse, C., and Rouil, L.: Aerosol modeling with CHIMERE: preliminary evaluation at the continental scale, Atmos. Environ., 38, 2803-2817, 2004.

Bian, H. and Prather, M.: Fast-J2: accurate simulation of stratospheric photolysis in global chemical models, J. Atmos. Chem., 41, 281-296, 2002.

Bian, H. and Zender, C. S.: Mineral dust and global tropospheric chemistry: relative roles of photolysis and heterogeneous uptake, J. Geophys. Res., 108, 4672, doi:10.1029/2002JD003143, 2003.

Bian, H., Prather, M. J., and Takemura, T.: Tropospheric aerosol impacts on trace gas budgets through photolysis, J. Geophys. Res., 108, 4242, doi:10.1029/2002JD002743, 2003.

Bowen, H. J. M.: Environmental Chemistry of the Elements, Academic Press, London, 1979.

Casasanta, G., di Sarra, A., Meloni, D., Monteleone, F., Pace, G., Piacentino, S., and Sferlazzo, D.: Large aerosol effects on ozone photolysis in the Mediterranean, Atmos. Environ., 45, 39373943, 2011.

Chen, F. and Dudhia, J.: Coupling an Advanced Land Surface/Hydrology Model with the Penn State/NCAR MM5 Modeling System. Part I: Model Implementation and Sensitivity, Mon. Weather Rev., 129, 569-585, 2001.

Davidson, J. A., Cantrell, C. A., Mcdaniel, A. H., Shetter, R. E., Madronich, S., and Calvert, J. G.: Visible-ultraviolet absorption sross sections for NO2 as a function of temperature, J. Geophys. Res., 93, 7105-7112, 1988.

Di Iorio, T., di Sarra, A., Sferlazzo, D. M., Cacciani, M., Meloni, D., Monteleone, F., Fuà, D., and Fiocco, G.: Seasonal evolution of the tropospheric aerosol vertical profile in the central Mediterranean and role of desert dust, J. Geophys. Res., 114, D02201, doi:10.1029/2008JD010593, 2009.

di Sarra, A., Cacciani, M., Chamard, P., Cornwall, C., DeLuisi, J. J., Di Iorio, T., Disterhoft, P., Fiocco, G., Fuà, D., and Monteleone, F.: Effects of desert dust and ozone on the ultravio- 
let irradiance at the Mediterranean island of Lampedusa during PAUR II, J. Geophys. Res., 107, PAU 2-1-PAU 2-14, doi:10.1029/2000JD000139, 2002.

di Sarra, A., Sferlazzo, D., Meloni, D., Anello, F., Bommarito, C., Corradini, S., and Di Iorio, T.: Empirical correction of multifilter rotating shadowband radiometer (MFRSR) aerosol optical depths for the aerosol forward scattering and development of a long-term integrated MFRSR-Cimel dataset at Lampedusa., Appl. Opt., 54, 2725-2737, doi:10.1364/AO.54.002725, 2015.

Diaz, J., Exposito, F., Torres, C., Herrera, F., Prospero, J., and Romero, M.: Radiative properties of aerosols in Saharan dust outbreaks using ground-based and satellite data: Applications to radiative forcing, J. Geophys. Res., 106, 18403-18416, 2001.

Dickerson, R. R., Stedman, D. H., and Delany, A. C.: Direct measurements of ozone and nitrogen dioxide photolysis rates in the troposphere, J. Geophys. Res.-Oceans, 87, 4933-4946, doi:10.1029/JC087iC07p04933, 1982.

Dubovik, O., Smirnov, A., Holben, B. N., King, M. D., Kaufman, Y. J., Eck, T. F., and Slutsker, I.: Accuracy assessments of aerosol optical properties retrieved from Aerosol Robotic Network (AERONET) Sun and sky radiance measurements, J. Geophys. Res.-Atmos., 105, 9791-9806, doi:10.1029/2000JD900040, 2000.

Favez, O., Cachier, H., Sciare, J., Alfaro, S. C., El-Araby, T., Harhash, M. A., and Abdelwahab, M. M.: Seasonality of major aerosol species and their transformations in Cairo megacity, Atmos. Environ., 42, 1503-1516, 2008.

Fuglestvedt, J. S., Jonson, J. E., and Isaksen, I. S. A.: Effects of reductions in stratospheric ozone on tropospheric chemistry through change in photolysis rates, Tellus, 46 B, 172-192, 1994.

Gardner, E., Sperry, P. D., and Calvert, J. C.: Primary quantum yields of $\mathrm{NO}_{2}$ photodissociation, J. Geophys. Res., 92, 66426652, 1987.

Gerasopoulos, E., Kazadzis, S., Vrekoussis, M., Kouvarakis, G., Liakakou, E., Kouremeti, N., Giannadaki, D., Kanadikou, M., Bohn, B., and Mihalopoulos, N.: Factors affecting $\mathrm{O}_{3}$ and $\mathrm{NO}_{2}$ photolysis frequencies measured in the eastern Mediterranean during the five-year period 2002-2006, J. Geophys. Res., 117, D22305, doi:10.1029/2012JD017622, 2012.

Ginoux, P., Chin, M., Tegen, I., Prospero, J. M., Holben, B., Dubovik, O., and Lin, S. J.: Sources and distributions of dust aerosols simulated with the GOCART model, J. Geophys. Res., 106, 20255-20273, 2001.

Granier, C., Artaxo, P., and Reeves, C. E. (Eds.): Emissions of Atmospheric trace Compounds, chap. Sea-salt aerosol source functions and emissions, Springer, 333-359, doi:10.1007/978-14020-2167-1_9, 2004.

Grell, G. and Devenyi, D.: A generalized approach to parameterizing convection combining ensemble and data assimilation techniques., Geophys. Res. Lett., 29, 38-1-38-4, doi:10.1029/2002GL015311, 2002.

Guinot, B., Cachier, H., and Oikonomou, K.: Geochemical perspectives from a new aerosol chemical mass closure, Atmos. Chem. Phys., 7, 1657-1670, doi:10.5194/acp-7-1657-2007, 2007.

Hauglustaine, D. A., Hourdin, F., Jourdain, L., Filiberti, M.A., Walters, S., Lamarque, J.-F., and Holland, E. A.: Interactive chemistry in the Laboratoire de Meteorologie Dynamique general circulation model: Description and background tropo- spheric chemistry evaluation, J. Geophys. Res., 109, D04314, doi:10.1029/2003JD003957, 2004.

Herich, H., Tritscher, T., Wiacek, A., Gysel, M., Weingartner, E., Lohmann, U., Baltensperger, U., and Cziczo, D. J.: Water uptake of clay and desert dust aerosol particles at sub- and supersaturated water vapor conditions, Phys. Chem. Chem. Phys., 11, 7804-7809, doi:10.1039/B901585J, 2009.

Hong, S. Y., Noh, Y., and Dudhia, J.: A new vertical diffusion package with an explicit treatment of entrainment processes, Mon. Weather Rev., 139, 2318-2341, 2006.

Kaufman, Y., Tanré, D., Dubovik, O., Karnieli, A., and Remer, L. A.: Absorption of sunlight by dust as inferred from satellite and ground-based remote sensing, Geophys. Res. Lett., 28, 1479-1482, 2001.

Keene, W. C., Sander, R., Pszenny, A. A. P., Vogt, R., Crutzen, P. J., and Galloway, J. N.: Aerosol pH in the marine boundary layer: a review and model evaluation, J. Aerosol Sci., 29, 339-356, 1998.

Kinne, S., Lohmann, U., Feichter, J., Schulz, M., Timmreck, C., Ghan, S., Easter, R., Chin, M., Ginoux, P., Takemura, T., Tegen, I., Koch, D., Herzog, M., Penner, J., Pitari, G., Holben, B., Eck, T., Smirnov, A., Dubovik, O., Slutsker, I., Tanre, D., Torres, O., Mishchenko, M., Geogdzhayev, I., Chu, D. A., and Kaufman, Y.: Monthly averages of aerosol properties: A global comparison among models, satellite data, and AERONET ground data, J. Geophys. Res., 108, 3-1-3-42, doi:10.1029/2001JD001253, 2003.

Kishcha, P., Nickovic, S., Starobinets, B., di Sarra, A., Udisti, R., Becagli, S., Sferlazzo, D., Bommarito, C., and Alpert, P.: Seasalt aerosol forecasts compared with daily measurements at the island of Lampedusa (Central Mediterranean), Atmos. Res., 100, 28-35, doi:10.1016/j.atmosres.2010.12.021, 2011.

Levy II, H., Horowitz, L. W., Schwartzkopf, M. D., Ming, Y., Jolaz, J.-C., Naik, V., and Ramaswamy, V.: The roles of aerosol direct and indirect effects in past and future climate change, J. Geophys. Res.-Atmos., 118, 4521-4532, doi:10.1002/jgrd.50192, 2013.

Mallet, M., Dulac, F., Formenti, P., Nabat, P., Sciare, J., Roberts, G., Pelon, J., Ancellet, G., Tanré, D., Parol, F., di Sarra, A., Alados, L., Arndt, J., Auriol, F., Blarel, L., Bourrianne, T., Brogniez, G., Chazette, P., Chevaillier, S., Claeys, M., D’Anna, B., Denjean, C., Derimian, Y., Desboeufs, K., Di Iorio, T., Doussin, J.-F., Durand, P., Féron, A., Freney, E., Gaimoz, C., Goloub, P., Gómez-Amo, J. L., Granados-Muñoz, M. J., Grand, N., Hamonou, E., Jankowiak, I., Jeannot, M., Léon, J.-F., Maillé, M., Mailler, S., Meloni, D., Menut, L., Momboisse, G., Nicolas, J., Podvin, J., Pont, V., Rea, G., Renard, J.-B., Roblou, L., Schepanski, K., Schwarzenboeck, A., Sellegri, K., Sicard, M., Solmon, F., Somot, S., Torres, B., Totems, J., Triquet, S., Verdier, N., Verwaerde, C., Wenger, J., and Zapf, P.: Overview of the ChemistryAerosol Mediterranean Experiment/Aerosol Direct Radiative Forcing on the Mediterranean Climate (ChArMEx/ADRIMED) summer 2013 campaign, Atmos. Chem. Phys. Discuss., 15, 19615-19727, doi:10.5194/acpd-15-19615-2015, 2015.

Marconi, M., Sferlazzo, D. M., Becagli, S., Bommarito, C., Calzolai, G., Chiari, M., di Sarra, A., Ghedini, C., Gómez-Amo, J. L., Lucarelli, F., Meloni, D., Monteleone, F., Nava, S., Pace, G., Piacentino, S., Rugi, F., Severi, M., Traversi, R., and Udisti, R.: Saharan dust aerosol over the central Mediterranean Sea: $\mathrm{PM}_{10}$ chemical composition and concentration versus optical 
columnar measurements, Atmos. Chem. Phys., 14, 2039-2054, doi:10.5194/acp-14-2039-2014, 2014.

Marticorena, B. and Bergametti, G.: Modelling the atmospheric dust cycle: 1-Design a soil-derived dust emissions scheme, J. Geophys. Res., 100, 16415-16430, 1995.

McPeters, R., Labow, G., and Johnson, B. J.: A satellite-derived ozone climatology for ballonsonde estimation of total column ozone, J. Geophys. Res., 102, 8875-8885, 1997.

Meloni, D., di Sarra, A., herman, J. R., Monteleone, F., and Piacentino, S.: Comparison of ground-based and TOMS erythemal UV doses at the island of Lampedusa in the period 1998-2003, J. Geophys. Res., 110, D01202, doi:10.1029/2004JD005283, 2005.

Menut, L., Bessagnet, B., Khvorostyanov, D., Beekmann, M., Blond, N., Colette, A., Coll, I., Curci, G., Foret, G., Hodzic, A., Mailler, S., Meleux, F., Monge, J.-L., Pison, I., Siour, G., Turquety, S., Valari, M., Vautard, R., and Vivanco, M. G.: CHIMERE 2013: a model for regional atmospheric composition modelling, Geosci. Model Dev., 6, 981-1028, doi:10.5194/gmd6-981-2013, 2013.

Menut, L., Mailler, S., Siour, G., Bessagnet, B., Turquety, S., Rea, G., Briant, R., Mallet, M., Sciare, J., Formenti, P., and Meleux, F.: Ozone and aerosol tropospheric concentrations variability analyzed using the ADRIMED measurements and the WRF and CHIMERE models, Atmos. Chem. Phys., 15, 6159-6182, doi:10.5194/acp-15-6159-2015, 2015a.

Menut, L., Rea, G., Mailler, S., Khvorostyanov, D., and Turquety, S.: Aerosol forecast over the Mediterranean area during July 2013 (ADRIMED/CHARMEX), Atmos. Chem. Phys., 15, 78977911, doi:10.5194/acp-15-7897-2015, 2015b.

Michalakes, J., Dudhia, J., Gill, D., Henderson, T., Klemp, J., Skamarock, W., and Wang, W.: The Weather Research and Forecast Model: Software Architecture and Performance, Proceedings of the Eleventh ECMWF Workshop on the Use of High Performance Computing in Meteorology, edited by: Mozdzynski, G., 25-29 October 2004, Reading, U.K., 2004.

Mischenko, M., Travis, L. D., and Lacis, A. A.: Scattering, absorption and emission of light by small particles, Cambridge University Press, Cambridge, 2002.

Monahan, E. C.: In The Role of Air-Sea Exchange in Geochemical Cycling, chap. The ocean as a source of atmospheric particles, Kluwer Academic Publishers, Dordrecht, Holland, 129163, 1986.

Nenes, A., Pilinis, C., and Pandis, S.: ISORROPIA: A new thermodynamic model for inorganic multicomponent atmospheric aerosols, Aquatic Geochem., 4, 123-152, 1998.

Pace, G., di Sarra, A., Meloni, D., Piacentino, S., and Chamard, P.: Aerosol optical properties at Lampedusa (Central Mediterranean). 1. Influence of transport and identification of different aerosol types, Atmos. Chem. Phys., 6, 697-713, doi:10.5194/acp-6-697-2006, 2006.

Petzold, A., Rasp, K., Weinzierl, B., Esselborn, M., Hamburger, T., Dornbrack, A., Kandler, K., Schultz, L., Knioppertz, P., Fiebig, M., and Virkkula, A.: Saharan dust absorption and refractive index from aircraft-based observations during SAMUM 2006, Tellus B, 61, 118-130, doi:10.1111/j.1600-0889.2008.00383.x, 2009.

Putaud, J.-P., Van Dingenen, R., Dell'Acqua, A., Raes, F., Matta, E., Decesari, S., Facchini, M. C., and Fuzzi, S.: Size-segregated aerosol mass closure and chemical composition in Monte $\mathrm{Ci}$ - mone (I) during MINATROC, Atmos. Chem. Phys., 4, 889-902, doi:10.5194/acp-4-889-2004, 2004.

Rea, G., Turquety, S., Menut, L., Briant, R., Mailler, S., and Siour, G.: Source contributions to 2012 summertime aerosols in the Euro-Mediterranean region, Atmos. Chem. Phys., 15, 80138036, doi:10.5194/acp-15-8013-2015, 2015.

Real, E. and Sartelet, K.: Modeling of photolysis rates over Europe: impact on chemical gaseous species and aerosols, Atmos. Chem. Phys., 11, 1711-1727, doi:10.5194/acp-11-1711-2011, 2011.

Remer, L. A., Kleidman, R. G., Levy, R. C., Kaufman, Y. J., Tanré, D., Mattoo, S., Vanderlei martins, J., Ichoku, C., Koren, I., Yu, H., and Holben, B. N.: Global aerosol climatology from the MODIS satellite sensors, J. Geophys. Res., 113, D14S07, doi:10.1029/2007JD009661, 2008.

Rosenfeld, D., Sherwood, S., Wood, R., and Donner, L.: Climate effects of aerosol-cloud interactions, Science, 343, 379-380, doi:10.1126/science.1247490, 2014.

Savoie, D. L., Maring, H. B., Izaguirre, M. A., Snowdon, T., and Custals, L.: Ground-based measurements of aerosol chemical, physical and optical properties during the Puerto Rico Dust Experiment (PRIDE), Eos Trans. AGU, 2000.

Sayer, A. M., Hsu, N. C., Bettenhausen, C., and Jeong, M.-J.: Validation and uncertainty estimates for MODIS collection 6 "Deep Blue" aerosol data, J. Geophys. Res., 118, 7864-7872, doi:10.1002/jgrd.50600, 2013.

Scheuvens, D., Schütz, L., Kandler, K., Ebert, M., and Weinbruch, S.: Bulk composition of northern African dust and its source sediments - A compilation, Earth-Sci. Rev., 116, 170-194, 2013.

Sciare, J., Oikonomou, K., Cachier, H., Mihalopoulos, N., Andreae, M. O., Maenhaut, W., and Sarda-Estève, R.: Aerosol mass closure and reconstruction of the light scattering coefficient over the Eastern Mediterranean Sea during the MINOS campaign, Atmos. Chem. Phys., 5, 2253-2265, doi:10.5194/acp-5-2253-2005, 2005.

Telford, P. J., Abraham, N. L., Archibald, A. T., Braesicke, P., Dalvi, M., Morgenstern, O., O’Connor, F. M., Richards, N. A. D., and Pyle, J. A.: Implementation of the Fast-JX Photolysis scheme (v6.4) into the UKCA component of the MetUM chemistry-climate model (v7.3), Geosci. Model Dev., 6, 161177, doi:10.5194/gmd-6-161-2013, 2013.

Turquety, S., Menut, L., Bessagnet, B., Anav, A., Viovy, N., Maignan, F., and Wooster, M.: APIFLAME v1.0: high-resolution fire emission model and application to the Euro-Mediterranean region, Geosci. Model Dev., 7, 587-612, doi:10.5194/gmd-7-5872014, 2014.

von Storch, H., Langenberg, H., and Feser, F.: A Spectral Nudging Technique for Dynamical Downscaling Purposes, Mon. Weather Rev., 128, 3664-3673, 2000.

Vuolo, M. R., Menut, L., and Chepfer, H.: Impact of transport schemes on modeled dust concentrations, J. Atmos. Oceanic Technol., 26, 1135-1143, 2009.

Wild, O., Zhu, X., and Prather, J.: Fast-J: accurate simulation of the in- and below-cloud photolysis in tropospheric chemical models, J. Atmos. Chem., 37, 245-282, 2000.

Ziemke, J. R., Chandra, S., Labow, G. J., Bhartia, P. K., Froidevaux, L., and Witte, J. C.: A global climatology of tropospheric and stratospheric ozone derived from Aura OMI and MLS measurements, Atmos. Chem. Phys., 11, 9237-9251, doi:10.5194/acp11-9237-2011, 2011. 